\title{
ANÁLISE DOS EFEITOS DA PRESCRIÇÃO EXTINTIVA NA ARBITRAGEM INTERNA E INTERNACIONAL, COM VISÃO A PARTIR DO DIREITO BRASILEIRO
}

\author{
Tese apresentada à Faculdade de Direito da \\ Universidade de São Paulo para a obtenção do \\ título de Doutor em Direito Internacional e \\ Comparado.
}

Área de Concentração: Direito Internacional e Comparado.

Orientador: Professor Titular Dr. Paulo Borba Casella.

Faculdade de Direito da Universidade de São Paulo

São Paulo, janeiro de 2011 


\section{PREÂMBULO: O OBJETO DA TESE}

Neste capítulo preambular, objetiva-se precipuamente apresentar o tema que será estudado, delineando as suas principais nuances, apresentando, ao final, as razões pelas quais este estudo representa contribuição para a ciência jurídica brasileira.

Para tanto, será necessário expor, em primeiro lugar, a justificativa para o tema escolhido (a), para em seguida expor a estrutura deste trabalho e notadamente a metodologia utilizada (b), assim como o escopo da tese (c).

Apresentadas essas considerações, será detalhado em que medidas o presente estudo contribui para a ciência jurídica brasileira (d).

\section{a) Justificativa do tema}

A harmonia e estabilidade das relações sociais são determinadas pelo tempo. $\mathrm{O}$ tempo exerce a sua influência no direito, uma vez que este determina prazos cuja finalidade é o adequado funcionamento da ordem jurídica, evitando-se transtornos aos operadores do direito, isto é, às partes, aos advogados, juízes e árbitros. Transtornos dos que mais inquietam o ser humano, como já dizia o José Rogério Cruz e Tucci, ${ }^{1}$ ou que promovem os mais desagregadores efeitos na sociedade, como entende Paulo Borba Casella. $^{2}$

Clóvis Beviláqua, ao analisar a importância do tempo às relações jurídicas, afirmou:

O tempo é o meio onde se realizam os acontecimentos humanos, e uma atividade, continuada em uma certa direção ou desviando-se de certa outra, não pode ser indiferente ao direito; a regulamentação das

\footnotetext{
1 "Não há dúvida de que entre os acontecimentos da natureza que mais inquietam o homem centra-se o fenômeno tempo." CRUZ E TUCCI, José Rogério. Tempo e processo. São Paulo: RT, 1997. p. 17.

2 Paulo Borba Casella, ao tratar do fundamento e da norma cogente de direito internacional, delimita o problema do decurso do tempo da seguinte forma: "A fundamentação pode ser intangível, mas não pode se socorrer de fundamentação metafísica ou metajurídica: há que ser encontrada no campo do direito, e a partir do reconhecimento da existência deste, fazer operar o direito e deste extrair (depois da existência) tanto validade quanto eficácia. E que estas se sustentem, não obstante as diferenças culturais, políticas e sobrevivam ao mais desagregador de todos os fatores: a inexorável passagem do tempo". CASELLA, Paulo Borba. Fundamentos do direito internacional pós-moderno. São Paulo: Quartier Latin, 2008. p. 738.
} 
relações opera-se de acôrdo com as circunstâncias e os acontecimentos de um determinado tempo, vive neles e com eles tece. Uma separação subitânea do direito ambiente, uma fragmentação da esfera jurídica, não é coisa necessária ao progresso; daí o princípio: o que se manteve durante um certo tempo pode tornar-se direito. ${ }^{3}$

Ainda, Soraya Amrani-Mekki, em tese sobre o tempo e o processo, sustenta que o tempo varia conforme as atividades sociais a ele relacionadas. Segundo esta autora, o tempo era concebido das diversas formas estabelecidas pelos meios sociais. E o meio social que constitui a atividade jurídica não escapa à regra desenvolvendo a sua própria concepção de tempo. ${ }^{4}$

Nessa linha de pensamento, isto é, na atividade jurídica, a influência do tempo é norma de caráter público e, apresentando múltiplas implicações no campo jurídico, ${ }^{5}$ é descrito, entre outras formas, por meio do instituto da prescrição extintiva.

A prescrição, seja a aquisitiva, seja a extintiva, constitui instituto jurídico que possui as suas raízes na Antiguidade, notadamente no sistema jurídico romano. Trata-se de um instituto onipresente nos regulamentos jurídicos em todo o mundo. ${ }^{6}$

O objetivo da prescrição é eminentemente de interesse social, cessando situações de incerteza e instabilidade, com a punição daquele que, inerte, não exerce seu direito.

\footnotetext{
${ }^{3}$ BEVILÁQUA, Clóvis. Teoria geral do direito civil. 7. ed. Rio de Janeiro: Editora Paulo de Azevedo, 1955. p. 267. Em idêntico sentido cita-se Carpenter, para quem "o decurso do tempo, quer sob a forma de prazo, quer sob a de prescrição, deve ter ingresso na parte geral do Código Civil, porque é um fato jurídico que influi sobre o nascimento e extinção de numerosas relações jurídicas e pode ser submetido a certas regras e preceitos gerais". CARPENTER, Luiz. F. Da prescrição. 3. ed. Rio de Janeiro: Nacional de Direito, 1958. p. 44.

${ }^{4}$ AMRANI-MEKKI, Soraya. Le temps et le procès civil. Tese, Paris I. Paris: Dalloz, 2002. p. 2. No original: "Le temps varie également selon les activités sociales concernées. G. GURVITCH a ainsi montré que le temps était conçu de façons aussi diverses qu'il exite de milieux sociaux. Le milieu social qui constitue l'activité juridique n'échappe pas à la règle et développe sa propre conception du temps".

${ }^{5}$ Para José Rogério Cruz e Tucci, "Na medida em que aflora inevitável e relevante para o dia a dia de cada cidadão no convívio social, o tempo também apresenta múltiplas implicações no campo do direito”. CRUZ E TUCCI, José Rogério. Tempo e processo. São Paulo: RT, 1997. p. 20.

${ }^{6}$ Nesse sentido, afirma Donaldo Armelin que a permanência da prescrição "no universo do direito durante séculos e, praticamente, a sua onipresença nos ordenamentos jurídicos atuais revelam a sua importância para a harmonia e segurança da vida social". ARMELIN, Donaldo. Prescrição e arbitragem. Revista de Arbitragem e Mediação, São Paulo: RT, n. 15, p. 66, out.-dez. 2007.
} 
Nesse sentido, Baudry-Lacantinerie e Tissier já diziam que a prescrição é um instituto necessário para a estabilidade de todos os direitos e que, sem ela, nada seria estável. ${ }^{7}$

Instituto conhecido e admitido há séculos pelo direito, a prescrição funciona, nas palavras de José Carlos Barbosa Moreira, como uma espécie de "escudo"8 protetor do devedor, de modo a extinguir a pretensão da eficácia autoral, pelo decurso do tempo. Ao menos segundo o direito brasileiro, a prescrição visa extinguir a pretensão. É o que dispõe o art. 189 do Código Civil: "Violado o direito, nasce para o titular a pretensão, a qual se extingue, pela prescrição, nos prazos a que aludem os arts. 205 e 206". 9

Quando se trata da aludida pretensão, pensa-se automaticamente em ação judicial, o meio processual mais adequado para que um magistrado diga o direito por meio do exercício da prestação jurisdicional.

No presente estudo, as atenções, apesar de focadas no direito de ação, visam à pretensão arbitral, notadamente no âmbito da arbitragem do comércio internacional.

$\mathrm{O}$ assunto que se pretende discutir na presente tese cinge-se à aplicação do instituto extintivo da pretensão - prescrição extintiva, no âmbito da arbitragem, seja na arbitragem interna (i), seja na arbitragem internacional (ii). Nesta última, os problemas relativos à prescrição tomarão um rumo mais amplo e complexo.

\section{(i) Arbitragem interna}

As relações entre as causas extintivas do direito de ação e a arbitragem comercial não foram objeto de praticamente nenhum debate, nem mesmo antes da

\footnotetext{
${ }^{7}$ BAUDRY-LACANTINERIE, G.; TISSIER, A. De La prescription. 4. ed. Paris: Librarie du Recueil Sirey, 1924. p. 20. No original: "La première pensée qu'éveillent dans l'esprit les définitions ci-dessous est que la prescription constitue une spoliation: le propriétaire est dépouillé de son droit de propriété, le créancier de son droit de créance. Mais on sait que la prescription est tout au contraire, une instituition nécessaire por la stabilité de tous les droits [...]. Rien ne serait stable sans la prescription. Un propriétaire ne serait jamais assuré de conserver son bien; un débiteur n'aurait jamais la certitude de ne pas être obligé de payer deux fois".

${ }^{8}$ Nesse sentido, v. José Carlos Barbosa Moreira: “[...] a prescrição não subtrai arma alguma do credor: cinge-se a fornecer ao devedor um escudo, do qual se poderá servir-se ou não, a seu talante". BARBOSA MOREIRA, José Carlos. O novo Código Civil e o direito processual. Revista Forense, Rio de Janeiro, v. 364, p. 186, 2002.

${ }^{9}$ A controvérsia sobre o objeto da prescrição, se ela atinge não só a pretensão, mas a ação ou o próprio direito no contexto de um procedimento arbitral, será analisada com precisão ao longo deste estudo.
} 
vigência da Lei n. ${ }^{\circ}$ 9.307/1996, que instituiu de forma completa o procedimento arbitral no Brasil.

A razão da ausência de qualquer debate a respeito da incidência da prescrição na arbitragem era óbvia: por ser a prescrição um instituto de direito material e a Lei Brasileira de Arbitragem um diploma processual, não haveria motivo para discussão a respeito da prescrição. Tudo se resolveria por meio da lei material.

Ademais disso, a Lei Brasileira de Arbitragem prevê a autonomia da vontade para a escolha do direito material aplicável à causa (art. 2. $.^{\circ} \S \S 1 .^{\circ}$ e $2 .^{\circ}$, da Lei $n .^{\circ}$ 9.307/1996), de modo que, diante dessa disposição, restaria prejudicada a ausência de dispositivo referente à prescrição no diploma arbitral brasileiro. ${ }^{10}$

A pouca ênfase dada a esta questão provavelmente se deu em razão de tanto a doutrina quanto a jurisprudência terem dirimido problemas que afetavam mais diretamente o instituto da arbitragem propriamente dito, como a autonomia da cláusula compromissória, o princípio segundo o qual o árbitro tem o poder de estatuir sobre a sua competência ("compétence-compétence"), o fenômeno da "judiciarização"11 da arbitragem, a homologabilidade das sentenças arbitrais estrangeiras, entre outros.

Mostrou-se, ao longo do tempo, que o caráter jurisdicional da arbitragem vinha cada vez ganhando mais força. Não só o fato de o caráter jurisdicional da sentença arbitral, mas em razão de o árbitro estar equiparado às funções do juiz estatal, e poder, segundo alguns, até mesmo proferir medidas cautelares de urgência, ${ }^{12}$ são fatores que demonstram a evolução do direito arbitral no Brasil e em todo o mundo.

\footnotetext{
${ }^{10}$ Nesse sentido, afirma Donaldo Armelin: “A Lei 9.307/96, que inseriu no ordenamento jurídico nacional a arbitragem, não cuidou dessa questão [prescrição], como é perfeitamente compreensível, considerandose a outorga nela existente às partes a escolha da lei processual e material a ser aplicada pelo árbitro ou tribunal arbitral”. ARMELIN, Donaldo. Prescrição e arbitragem. Revista de Arbitragem e Mediação, São Paulo: RT, n. 15, p. 65, out.-dez. 2007.

${ }^{11}$ O fenômeno da "judiciarização" da arbitragem (ao menos da arbitragem internacional) fora, há tempos, denunciada por Bruno Oppetit: “[...] alors que l'arbitrage international, victime, comme on l'a bien démontré (9), de la déviation processuelle, tend trop souvent à s'engluer dans d'interminables débats de procédures, pré-, para ou post-arbitrale, qui font perdre de vue le règlement du fond du litige, au point que l'on se torne maintenant parfois vers des méthodes alternatives de règlement des différends...". OPPETIT, Bruno. Justice étatique et justice arbitrale. Études offertes à Pierre Bellet. Paris: Litec, 1991. p. 417-418.

12 Sobre este assunto ver notadamente CARMONA, Carlos Alberto. Arbitragem e processo: um comentário à Lei n. ${ }^{\circ}$ 9.307/96. 3. ed. São Paulo: Atlas, 2009. pp. 322/330; VALENÇA FILHO, Clávio de Melo. Tutela judicial de urgência e a lide objeto de convenção de arbitragem. Revista Brasileira de
} 
Entretanto, existem certas questões que até hoje não foram dirimidas (ou mesmo exploradas) nem pela doutrina tampouco pela jurisprudência, e que podem restringir em certo ponto não só o caráter jurisdicional da arbitragem, como limitar o exercício de agir dentro da esfera arbitral: trata-se aqui das causas extintivas de pretensões, notadamente da prescrição extintiva, prevista não só na legislação civil brasileira, como em outras legislações em todo o mundo.

$\mathrm{O}$ assunto revela-se importante e sinuoso, eis que, para se chegar a uma resposta concreta sobre a aplicabilidade da prescrição extintiva na arbitragem, é preciso delinear, com precisão, os conceitos de jurisdição estatal e jurisdição arbitral, além de demonstrar a processualidade e a materialidade do instituto arbitral.

A evolução da prática da arbitragem em diversos países, principalmente da Europa Ocidental, prova que o seu caráter jurisdicional é cada vez mais acentuado, não deixando dúvidas acerca dos poderes do árbitro para conduzir com total independência o procedimento arbitral, além de assimilar, mas sem incorporar, certas características da legislação processual à arbitragem.

A prescrição é um fato jurídico. O transcurso do tempo exerce considerável influência nas relações entre as pessoas, atribuindo ao Código Civil Brasileiro (CCB) efeitos cujas repercussões afetam a própria pretensão. Isso porque, para garantir a tranquilidade da ordem jurídica, preservando a estabilidade e a segurança das relações sociais, o titular de uma pretensão deve exercê-la em certo lapso temporal.

Em termos gerais, como leciona Francisco Amaral, três são os elementos primordiais para que a prescrição ocorra. São eles: a) um direito subjetivo lesado, do qual necessariamente nasce uma pretensão de ressarcimento; b) a não exigência do cumprimento do respectivo dever, ou do ressarcimento do dano; c) o decurso do prazo que a lei prefixa. ${ }^{13}$

Arbitragem, Porto Alegre: Thomson-IOB, ano II, n. 7, p. 7 e ss., jul.-set. 2005; e COSTA, Nilton César Antunes da. Poderes do árbitro: de acordo do com a Lei 9.307/96. São Paulo: RT, 2002.

${ }^{13}$ AMARAL, Francisco. Direito civil: introdução. 3. ed. Rio de Janeiro: Renovar, 2000. p. 562. 
Essa é a ideia central do instituto da prescrição extintiva: a inércia do titular de uma pretensão e o decurso do tempo.

Considerado um instituto de direito material, a prescrição extintiva encontra-se regulamentada, de forma apropriada, no CCB. A lei processual civil brasileira - o Código de Processo Civil (CPC) - apenas estabelece determinados efeitos que a prescrição pode causar no processo, como é o caso da expiração dos efeitos do prazo prescricional, assim como as regras formais acerca da interrupção da prescrição (por exemplo, a retroeficácia prevista no art. $219, \S 1$. $^{\circ}$ do CPC).

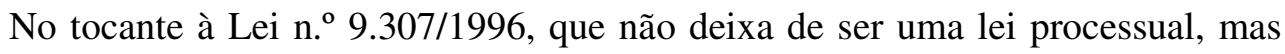
dedicada do "processo arbitral", não se vislumbram quaisquer regras sobre prescrição ou mesmo a remissão a determinadas regras de prescrição previstas no CCB. Em razão desse "silêncio", surgem problemáticas interessantes: a inércia do titular de um direito pode ser punida e arguida em sede arbitral? Como se operacionaliza a interrupção da prescrição em sede arbitral? A notificação de uma parte demandada (que havia subscrito com outra parte uma convenção de arbitragem) para responder a uma demanda de arbitragem configuraria "citação válida", prevista na legislação processual civil brasileira, possuindo o efeito de interromper o prazo prescricional? Como se enquadra, na arbitragem, o princípio da ordem pública, do qual é revestido o instituto da prescrição extintiva? Pode o árbitro julgar uma demanda ex officio, se verificar que a pretensão arbitral está prescrita? Pode o árbitro, diante do princípio da autonomia da vontade, um dos pilares da arbitragem, permitir que as partes modifiquem os prazos prescricionais? De que forma tais questões interferem no plano internacional?

Na realidade, é preciso saber se existe a possibilidade de alguém que descumpriu uma relação contratual e estipulou convenção de arbitragem possuir tempo indefinido para discussão de qualquer controvérsia na arbitragem, e, finalmente, qual a influência do tempo no procedimento arbitral, tendo em vista o princípio segundo o qual o fator temporal exerce a sua influência no meio jurídico, através do instituto da prescrição extintiva, primando pelo interesse social, seja no âmbito interno, seja no âmbito do direito internacional.

\section{(ii) Arbitragem internacional}


Em matéria internacional, o problema colocado pelo decurso do tempo é ainda mais complexo. A qualificação do instituto da prescrição extintiva em matéria internacional, a determinação da lei aplicável à prescrição nos conflitos internacionais e a manifestação da ordem pública internacional relativamente aos prazos prescricionais inseridos no contexto dos litígios da arbitragem comercial internacional ${ }^{14}$ são questões pouco debatidas, cujo estudo será o grande foco desta tese.

As questões internacionais envolvendo o instituto da prescrição extintiva, e que poderiam ser eventualmente suscitadas em um procedimento arbitral internacional, são bastante densas e exigem um estudo aprofundado.

As dúvidas postas sobre a aplicabilidade e efeitos da prescrição extintiva, no âmbito internacional (o que vale para as arbitragens internacionais), foram levantadas por Fayez Hague-Chanine, em seu curso proferido na Academia de Direito Internacional da Haia no ano de 1995:

A diversidade das normas aplicáveis à prescrição deixa porta aberta à questão de saber se a prescrição em direito internacional privado pode ser regulada por norma pertencente a outro direito, senão o direito internacional e o direito convencional, e os ultrapassaria, como direito supranacional ou transnacional? [...] Por outro lado, o contrato dito sem lei pode dar origem a uma obrigação. A prescrição deste estaria submetida à lex mercatoria? ${ }^{15}$

\footnotetext{
${ }^{14}$ A presente tese ao mencionar a expressão "arbitragem comercial internacional" refere-se à arbitragem propensa a resolver os litígios oriundos, essencialmente, do comércio internacional. Não será tratada a arbitragem "internacional" no sentido do direito internacional público, como é o caso das arbitragens emanadas do International Centre For Settlement of Investment Disputes (ICSID), que resolve conflitos entre o Governo de um país e uma pessoa jurídica privada e fundamenta na Convenção sobre a Resolução de Conflitos relativos a Investimentos entre Estados e Nacionais de outros Estados, assinada em Washington em 18.03.1965. Sendo assim, a tese, quando se referir à internacionalidade da arbitragem, utilizará a expressão "arbitragem internacional". No mesmo sentido, v. Phlippe Fouchard quando da publicação de seu artigo Quand un arbitrage est-il international?: "On ne traitera ici que de l'arbitrage commercial international, et, non évidemment de l'arbitrage de droit international public; néanmoins, il convient d'entendre assez largement, en l'ocurrence, la 'commercialité', pour considérer qu'elle englobe toute relation économique et introduire dans notre sujet, notamment les arbitrages intéressant un État ou une personne morale de droit public d'une part, et une entreprise privée d'autre part, à l'occasion, par exemple, de litiges relatifs aux investissements (Convention de Washington du 18 mars 1965)". FOUCHARD, Philippe. Quand un arbitrage est-il international?. Phlippe Fouchard: Écrits - Droit de l'arbitrage e droit du commerce international. Paris: Comitê français de l'arbitrage, 2007. p. 251.

${ }^{15}$ HAGE-CHANINE, Fayez. La prescription extintive en droit international privé. Tradução de Paulo Borba Casella. Recueil des cours de l'académie de droit international de La Haye, t. 255, p. 336-337, 1995. In: CASELLA, Paulo Borba. Fundamentos do direito internacional pós-moderno. São Paulo: Quartier Latin, 2008. p. 738-739.
} 
A grande justificativa para o estudo aprofundado dos efeitos da prescrição extintiva no contexto de uma arbitragem internacional está na verdadeira essência da teoria geral do direito internacional privado: o estudo da teoria das qualificações e do conflito de leis.

Com efeito, o estudo da qualificação da prescrição em direito internacional privado revela-se importante para que se determine a lei aplicável à prescrição.

Ainda mais, partindo-se do pressuposto de que os árbitros não possuem "foro", isto é, não estão necessariamente vinculados à lex fori, ${ }^{16}$ e que a arbitragem internacional é provida de plena autonomia, sendo independente de qualquer direito nacional, os problemas relativos à qualificação da prescrição tornam-se ainda maiores, eis que seria preciso determinar não apenas a lei aplicável à prescrição, mas a lei qualificadora do mesmo instituto.

A assimilação da prescrição a um instituto de ordem pública torna o problema ainda mais amplo, sobretudo quando se pensa na eficácia das sentenças arbitrais estrangeiras, notadamente quando a discussão se dá em torno da execução de um julgado em que houve a ocorrência de prescrição.

Portanto, é com base em profundo estudo do instituto da prescrição extintiva, suas origens, sua razão de ser, que se poderá ter um fundamento para delimitar o âmbito da aplicabilidade da prescrição no contexto de uma arbitragem internacional.

Ante a escassa discussão da doutrina nacional e estrangeira sobre esse assunto e em vista do pouco número de julgados sobre a mesma questão é que o presente estudo ganha interesse, e, com o condão de preencher uma lacuna no direito arbitral,

\footnotetext{
${ }^{16}$ A não submissão dos árbitros à lex fori, seja em matéria de arbitragem interna, seja internacional, é explicada com clareza por Antoine Kassis: 'L'arbitre n'est pas l'organe d'un ordre juridique étatique, il n'est pas investi de sa mission par l'État, et il ne tranche pas les litiges au nom d'un État et il n'est donc pas le gardien d'un ordonnancement juridique étatique. L'arbitre est un juge privé choisi et investi de sa mission par les parties qui sont ses "créateurs"”. E, dessa forma, conclui o referido autor: "L'arbitre, contrairement au juge étatique, n'a pas de lex fori. Cela est vrai de tout arbitre, que l'arbitrage soit interne, soit international". KASSIS, Antoine. La reforme du droit de l'arbitrage international: Réflexions sur le texte proposé par le Comité français de l'arbitrage. Paris: L'Harmattan, 2008. p. 98.
} 
notadamente no direito arbitral internacional, será analisada uma proposta de solução à interpretação das questões relativas à prescrição extintiva no âmbito da arbitragem.

Harmonizar os prazos prescricionais e as questões sobr prescrição como um todo? Uniformizar o direito de prescrição em âmbito internacional? Trata-se de questões que, como afirma Bénédicte Fauvarque-Cosson, constituem os objetivos inerentes ao direito comparado, disciplina vista por muitos como de caráter especulativo, ${ }^{17}$ mas que contribui para a delimitação da problemática aqui exposta.

Para tanto, é necessário definir uma estrutura de trabalho de modo a entrelaçar as ideias a que se propõe estudar de maneira lógica, atentando sempre para o prisma do direito comparado, isto é, o estudo comparativo de diferentes leis estrangeiras, do direito de países com sistema jurídico diverso (civil law e common law), cujas premissas, convergências e divergências são essenciais para definir uma proposta de interpretação. É o que será explanado no ponto seguinte.

\section{b) Estrutura da tese e metodologia utilizada}

A tese será estruturada por meio da divisão de duas grandes partes interligadas, sendo a segunda uma decorrência lógica da primeira.

Inicialmente, será delimitado o campo teórico da tese. Para tanto, serão analisados em pormenor os conceitos de arbitragem interna e internacional, assim como a definição da prescrição extintiva.

Em seguida, ainda na primeira parte, será contextualizada a aplicabilidade da prescrição extintiva em sede de arbitragens internacionais. Dessa forma, serão estudadas a conceituação e qualificação da prescrição em âmbito de direito internacional privado, sempre tendo em mente a realização de um procedimento arbitral.

\footnotetext{
${ }^{17}$ FAUVARQUE-COSSON, Bénédicte. Aspects de droit comparé de la prescription. Les désordres de La prescription. Textes réunis par Patrick Courbe. Rouen: Publications de l'Université de Rouen avec le concours du Centre de recherche em droit des activités professionnelles, 2000. p. 44.
} 
A segunda parte da tese será a consequência da primeira, isto é, apresentados os contornos da prescrição extintiva no âmbito da arbitragem internacional, notadamente a sua razão de ser, serão examinados os mais diversos reflexos da prescrição no contexto de um procedimento arbitral, em todas as fases deste último. A análise desse ponto terá como pressuposto básico a visão a partir do direito brasileiro.

Sendo a prescrição qualificada de forma diversa pelos países da família romanogermânica (civil law) como uma questão de caráter substancial e nos países do judgemade law (common law), especialmente os Estados Unidos da América e a Inglaterra, como uma questão processual, ${ }^{18}$ tais reflexos, por uma razão própria, serão tratados mediante uma análise comparativista, com verificação de determinadas legislações estrangeiras de países que adotam ambos os mencionados sistemas de direito. ${ }^{19}$

Portanto, mesmo levando-se em conta que não se considera o direito comparado como tão somente um método, mas sim uma disciplina jurídica autônoma, a abordagem das questões propostas nesta parte será feita por meio de uma comparação global do tema com base em diversas legislações estrangeiras, incluindo-se as leis, doutrina, jurisprudência e fontes estrangeiras comparadas, ${ }^{20}$ de países em que a arbitragem

\footnotetext{
${ }^{18}$ A distinção do objeto da prescrição entre os países da família romano-germânica e de common law revela-se bastante importante para o direito comparado. Esta distinção restou, inclusive, objeto do comentário realizado pela United Nations Office of Legal Affairs quando da elaboração da Convenção sobre Prescrição em matéria de venda internacional de mercadorias assinada em Nova York no ano de 1974. Confira-se o seguinte trecho do referido comentário: "Perhaps even more serious is the uncertainty as to which national law will be applicable to an international sales transaction. Apart from the problems of choice of law that customarily arise in international transaction, problems of prescription or limitation present a special difficulty of characterization or qualification: some legal systems consider these rules as 'substantive' and therefore must decide which national law is applicable; other systems consider them as part of 'procedural' rules of the forum; still other legal systems follow a combination of the above apoproaches". Este comentário, de responsabilidade da United Nations Office of Legal Affairs, realizado pelo Professor Kazuaki Sono, da Universidade de Hokkaido, Japão, pode ser encontrado na internet no seguinte endereço eletrônico: <http://www.uncitral.org/pdf/english/yearbooks/yb-1979-e/vol10-p145173-e.pdf>, p. 147.

${ }^{19}$ Sobre as diferenças exisentes entre o tratamento da prescrição extintiva nos países de common law e civil law explica Bénédicte Fauvarque-Cosson: "Pour un juriste de common law, l'expression 'prescription extintive' semble contradictoire, car la notion de prescription sert à nommer le mécanisme qui permet d'acquérir des droits, non de les éteindre. C'est en réalité le concept de Limitation of Action qui équivaut à notre prescription extintive". FAUVARQUE-COSSON, Bénédicte. Aspects de droit comparé de la prescription. Les désordres de La prescription. Textes réunis par Patrick Courbe. Rouen: Publications de l'Université de Rouen avec le concours du Centre de recherche em droit des activités professionnelles, 2000. p. 45.

${ }^{20}$ Nesse sentido, v. Bénédicte Fauvarque-Cosson: "Since comparative law consists primarily of the application of the comparative method, it should include comparisons among internal, international, European, as well as foreign sources of law" (Development of Comparative Law in France. In: REIMANN, Mathias; ZIMMERMANN, Reinhard (Ed.). The Oxford Handbook of Comparative Law. Oxford: Oxford University Press, 2008 p. 38).
} 
internacional já alcançou maior desenvolvimento, de modo a identificar as soluções já contempladas em diversos ordenamentos, transportando-as para o direito brasileiro, se necessário.

O estudo da arbitragem internacional em uma perspectiva comparativista é, aliás, fato relevante nesses dias em que, na ausência de uma regra adequada a ser a aplicada em um conflito entre partes de diferente nacionalidade, envolvendo negócios jurídicos típicos do comércio internacional, buscam os árbitros preencher uma lacuna do direito aplicável por meio de soluções advindas do direito comparado. ${ }^{21}$

O objetivo deste estudo é, em síntese, encontrar, por meio do direito comparado, soluções que possam preencher a lacuna jurídica resumida pelos efeitos da prescrição extintiva no âmbito da arbitragem interna e internacional, observando os diferentes sistemas legais, suas convergências e divergências, até que se chegue a um denominador comum. $^{22}$

\section{c) Alcance da tese}

O presente trabalho busca analisar apenas os efeitos do instituto da prescrição extintiva no âmbito dos litígios que interessam ao comércio internacional, isto é, dar-seá ênfase aos reflexos da prescrição extintiva sobre a arbitragem, notadamente a arbitragem internacional, principalmente aquelas que se desenvolvem sob a égide da Câmara de Comércio Internacional (CCI).

Sendo os litígios do comércio internacional resolvidos, em sua grande parte, por arbitragem, o grande interesse deste estudo é, como anteriormente frisado, preencher

\footnotetext{
21 Nesse sentido, sustenta Bénédicte Fauvarque-Cosson: "International commercial arbitration has become a particularly important context for the use of comparative law in recent years. A comparative approach not only brings a sense of legitimacy to the process, it is also useful as source of law. Arbitrators often like to refer to a variety of legal sources in order to justify the application of one national rule instead of another, or in order to fill a gap when there is no satisfactory solution in domestic law" (Development of Comparative Law in France. In: REIMANN, Mathias; ZIMMERMANN, Reinhard (Ed.). The Oxford Handbook of Comparative Law. Oxford: Oxford University Press, 2008. p. 59-60).

${ }^{22}$ Nesse sentido, Bénédicte Fauvarque-Cosson, ao citar Saleilles e Lambert, afirmou: "Saleilles and Lambert observed that comparative Law, as a legal science, extends beyond observation and discovery of foreign legal systems to influence domestic law and prompt a convergence among different legal regimes. Their conception of comparative law was ambitiously oriented towards the discovery of universal law" (Development of Comparative Law in France. In: REIMANN, Mathias; ZIMMERMANN, Reinhard (Ed.). The Oxford Handbook of Comparative Law. Oxford: Oxford University Press, 2008. p. 43).
} 
uma lacuna do direito arbitral, principalmente no âmbito do direito internacional, analisando a razão de ser e os efeitos da prescrição extintiva na arbitragem internacional.

Portanto, o presente estudo excluirá a análise, em profundidade, dos institutos da decadência e da prescrição aquisitiva. A razão para essa exclusão é detalhada a seguir.

Primeiramente, no que tange ao instituto da decadência, apesar de se considerar um instituto intimamente ligado à prescrição extintiva, a presente tese não o analisará de forma profunda, uma vez o que os efeitos da decadência assimilam-se aos da prescrição, com a diferença de que a decadência tem por objeto o exercício de direito potestativo, e interessa ao próprio litígio em si, dependendo da lei aplicável ao mérito da controvérsia.

Ainda assim, as indagações a respeito da aplicação do instituto da prescrição no procedimento arbitral valem também para a decadência, que é considerada matéria de ordem pública material, à luz do direito brasileiro (art. 210 do CCB).

A decadência é causa extintiva de direito pelo seu não exercício no prazo estipulado pela lei. Para Agnelo Amorim Filho, ${ }^{23}$ “o prazo previsto expressamente em lei, para exercício das pretensões que se ajuízam mediante ação constitutiva, positiva ou negativa, é de decadência, pois a pretensão constitutiva se caracteriza como direito potestativo".

Aplicada à arbitragem, a decadência poderá sem dúvida ser matéria de arguição por uma das partes na instância arbitral, em razão de determinada matéria de fundo que trate de uma questão em que corra eventualmente prazo decadencial para uma das partes. Assim como na prescrição, os árbitros poderão, em princípio, apreciar o pedido de decadência e decidir a respeito, ${ }^{24}$ com base na lei que for aplicável ao mérito, no procedimento arbitral.

\footnotetext{
23 AMORIM FILHO, Agnelo. Critério científico para distinguir a prescrição da decadência e para identificar as ações imprescritíveis. Revista dos Tribunais, São Paulo, n. 744, p. 725, e n. 300, p. 7.

${ }^{24}$ Sobre o disposto no art. 210 do CCB ("Deve o juiz, de ofício, conhecer da decadência, quando estabelecida por lei”), ainda é prematuro afirmar que tal hipótese também cabe ao árbitro na instância arbitral.
} 
Apesar de a decadência ser uma das formas de extinção de direitos prevista na legislação civil brasileira, a análise desse instituto dentro do escopo do trabalho que se pretende realizar é praticamente a mesma da prescrição. Como esta última é dotada de aspectos mais peculiares do que a decadência (por exemplo, a questão da interrupção ou da prescrição intercorrente), no presente estudo dar-se-á uma maior ênfase ao instituto da prescrição e sua aplicação na arbitragem interna e internacional.

Assim sendo, ao longo do trabalho, será mencionado o instituto da decadência, mas tão somente para distinguir situações em que o prazo extintivo aplicável seria o decadencial, e não o prescricional, mas sem distinguir, cientificamente, esses dois citados institutos, questão que não será objeto desta tese.

Quanto à prescrição aquisitiva, ela também não será contemplada nesta tese. A prescrição aquisitiva, como leciona Caio Mário da Silva Pereira, refere-se ao instituto da usucapião, isto é,

[...] a aquisição do direito real pelo decurso do tempo, instituída em favor daquele que tiver, como ânimo de dono, o exercício de fato das faculdades inerentes ao domínio, ou a outro direito real, relativamente a coisas móveis ou imóveis, por um período prefixado pelo legislador. ${ }^{25}$

Os requisitos fundamentais da prescrição aquisitiva são o decurso do tempo e a posse. Absolutamente, são diversos os requisitos e efeitos da prescrição aquisitiva e prescrição extintiva. $^{26}$

\footnotetext{
${ }^{25}$ PEREIRA, Caio Mário da Silva. Instituições de direito civil. 18. ed. Rio de Janeiro: Forense, 1997. v. 1, p. 434.

${ }^{26}$ Nesse sentido, afirma Caio Mário da Silva Pereira: “[...] não se pode na verdade confundir prescrição aquisitiva (Ensitzunc, forma de aquisição de direitos reais) com a extintiva (Verjährung, modalidade de perecimento de direito, com a ação respectiva, e todos os meios defensivos)". PEREIRA, Caio Mário da Silva. Instituições de direito civil. 18. ed. Rio de Janeiro: Forense, 1997. v. 1, p. 434. Adota posição, nesse mesmo aspecto, Antonio Luís da Câmara Leal: "Até aqui, o usucapião, meio aquisitivo da propriedade, e a prescrição longi et longissimi temporis, meio extintivo da reivindicatória, conservaram-se como institutos diversos, constituindo um: título de aquisição da propriedade e representando outro: simples exceção processual contra a reivindicação". Prossegue o referido autor rebatendo com veemência da teoria monista da prescrição ao afirmar: "Estamos com os dualistas, porque nos repugna admitir a unidade conceitual das prescrições aquisitiva e extintiva, quando nela deparamos uma tríplice diversidade de objeto, condições e efeitos. CÂMARA LEAL, Antonio Luís da. Da prescrição e da decadência. 2. ed. atual. por José de Aguiar Dias. Rio de Janeiro: Forense, 1959. p. 19-21.
} 
Sendo assim, no estudo em foco, cuidar-se-á apenas da inércia do titular, que dá ensejo à prescrição extintiva, não havendo matéria a ser tratada a respeito da prescrição aquisitiva.

Finalmente, observe-se que o presente estudo contemplará a incidência da prescrição extintiva em matéria de direito arbitral interno e direito internacional privado. Em relação a este último, sua análise torna-se de vital importância de modo a entender como a questão relativa aos efeitos da prescrição extintiva se aplica às arbitragens internacionais.

Portanto, no âmbito da arbitragem interna, as considerações a serem colocadas tomarão como base a Lei n. ${ }^{\circ} 9.307 / 1996$, e, em sede de arbitragem internacional, o estudo contemplará a arbitragem proveniente do comércio internacional, entre particulares, não sendo vislumbrada a arbitragem entre Estados, em que a discussão se volte em torno das soluções de controvérsias típicas do direito internacional público.

\section{d) A contribuição do presente estudo à ciência jurídica brasileira}

Como já frisado nos itens anteriores, o objetivo do presente estudo é preencher uma lacuna do direito brasileiro.Um lacuna do direito material cujos reflexos incidem diretamente no procedimento arbitral. Se no âmbito interno uma eventual reforma legislativa seria viável, no âmbito internacional o objetivo é encontrar soluções de modo que as diversas questões acerca da prescrição extintiva estejam em sintonia com a essência da arbitragem internacional.

Os princípios que norteiam e regulam o decurso do tempo - a saber, a necessidade de consolidar a estabilidade das relações jurídicas e a consequente pacificação social - devem estar positivados de modo a causar reflexos no âmbito da arbitragem, sobretudo na esfera da arbitragem internacional. Questões como a forma da interrupção da prescrição, duração do prazo e o fundamento da prescrição são exemplos que podem ser vistos de modo a se ter uma possível uniformização da matéria no âmbito internacional. 
Fayez Hage-Chanine, em seu curso na Haia em 1995, citando Bigot de Préameneu (um dos principais redatores do Código Civil francês), afirmou que a prescrição "introduz a paz nas relações humanas eliminando os problemas e perturbações que poderiam ser causados pelos processos tardios". Complementa, sustentando que, "de todas as instituições do direito civil, a prescrição é a mais necessária à ordem social", ${ }^{27}$

Ao finalizar a referida conferência proferida na Academia de Direito Internacional, Fayez Hage-Chanine, encontrando apoio no mesmo Bigot de Préameneu, chegou à derradeira conclusão, segundo a qual a prescrição é, de todas as instituições jurídicas, a mais importante à ordem social, não só no plano interno, mas também no âmbito do direito internacional privado. No entanto, as conclusões tiradas pelo dito autor baseavam-se à luz dos litígios do direito internacional privado. Nada fora tratado em relação aos litígios existentes na seara interna ou internacional que são resolvidos pela via da arbitragem.

A manutenção da ordem social propugna um estudo da aplicabilidade da prescrição no âmbito da arbitragem, tanto interna quanto internacional.

A contribuição do presente estudo à ciência jurídica brasileira encontra-se, portanto, na necessidade de disciplinar determinadas questões relativas à prescrição extintiva no âmbito da arbitragem, tanto a interna quanto a internacional, fazendo cessar incertezas e primando pela estabilidade social.

Portanto, as conclusões a serem tiradas deste estudo guiarão a melhor forma de regular o decurso do tempo no âmbito da arbitragem, o que poderá se dar por meio de uma reforma de legislação ou até mesmo complementando tratados internacionais.

\footnotetext{
${ }^{27}$ HAGE-CHANINE, Fayez. La prescription extintive en droit international privé. Tradução de Paulo Borba Casella. Recueil des cours de l'académie de droit international de La Haye, t. 255, p. 239, 1995.
} 


\section{INTRODUÇÃO}

O objetivo do presente estudo é realizar uma análise do instituto da prescrição extintiva e seus efeitos no contexto de um procedimento arbitral, seja ele interno ou internacional.

No direito brasileiro, a Lei n. ${ }^{\circ}$ 9.307, de 23.09.1996, instituiu, definitivamente, a arbitragem como um método alternativo de resolução de controvérsias. Ficou estabelecido, após o advento dessa lei, que "as pessoas capazes de contratar poderão valer-se da arbitragem para dirimir litígios relativos a direitos patrimoniais disponíveis". ${ }^{28}$ A partir desta disposição, o direito subjetivo de ação ficou ampliado pelo ordenamento jurídico brasileiro, eis que restou institucionalizado o direito de resolver litígios sob o âmbito de uma nova jurisdição - a jurisdição arbitral. A limitação do direito de agir dava-se tão somente em razão da capacidade da parte e da livre disponibilidade de direitos.

Ficou ainda definido na sobredita lei que as partes poderiam prever, em suas transações comerciais, a estipulação de que todos os litígios advindos dos referidos instrumentos contratuais seriam resolvidos por arbitragem. Tratava-se aí da instituição da chamada cláusula compromissória, aquela que Fouchard, Gaillard e Goldman classificam como a "convenção através da qual as partes signatárias de um contrato decidem submeter à arbitragem os litígios que poderiam, relativamente, nascer daquele contrato". 29

Igualmente, adotou-se, de forma definitiva no direito brasileiro, a teoria da autonomia da convenção de arbitragem (art. $8^{\circ}$ da Lei n. ${ }^{0}$ 9.307/1996) e do princípio, segundo o qual o árbitro estatui sobre a sua própria competência (compétencecompétence). ${ }^{30}$ De certo modo, o direito brasileiro incorporou em seu ordenamento os

\footnotetext{
${ }^{28}{\text { Art. } 1 .^{\circ} \text { da Lei n. }{ }^{\circ} 9.307 / 1996 .}^{2}$

${ }^{29} \mathrm{Na}$ versão original (tradução livre): “convention par laquelle les parties à un contrat s'engagent à soumettre à l'arbitrage les litiges qui pourraient naître relativement à ce contrat”. FOUCHARD, Philippe; GAILLARD, Emmanuel; GOLDMAN, Berthold. Traité de l'arbitrage commercial international. Paris: Litec, 1996. p. 209.

${ }^{30}$ Além de sua autonomia, a convenção de arbitragem é provida de dois efeitos: em primeiro lugar, um efeito negativo, dado que, quando as partes inserem uma cláusula compromissória, elas declaram, tacitamente, a incompetência do juiz estatal para conhecer das questões visadas pela cláusula. Logo após,
} 
princípios fundamentais da arbitragem, sem os quais fariam com que o instituto arbitral perdesse a sua razão de ser. A partir daí, a arbitragem configurava-se, de uma maneira geral, um procedimento ${ }^{31}$ totalmente autônomo em relação ao processo judicial, dotado de aparelhagem própria. $^{32}$

Uma questão, é certo, jamais foi considerada pelo legislador quando da elaboração da Lei n. ${ }^{\circ}$ 9.307/1996: os efeitos do decurso do tempo. Nesta tese, quando se fala em decurso do tempo, a referência é ao instituto da prescrição extintiva.

Talvez o silêncio do legislador tenha se dado por motivos óbvios: a prescrição extintiva constitui um instituto de direito material, e por isso é contemplada no CCB ou em determinada lei material. ${ }^{33}$ Dessa forma, todas as questões sobre prescrição que eventualmente surgissem no curso de uma arbitragem realizada no Brasil, sob a égide da Lei n. ${ }^{\circ}$ 9.307/1996, por exemplo, hipóteses de suspensão e interrupção da prescrição, definição do termo inicial, duração do prazo, ${ }^{34}$ entre outras, seriam necessariamente remetidas ao $\mathrm{CCB}$.

a convenção de arbitragem é provida de um efeito positivo: ela obriga as partes a submeter aos árbitros todos os litígios decorrentes do contrato visados pela cláusula e fundamenta a competência do tribunal arbitral (FOUCHARD, Philippe; GAILLARD, Emmanuel; GOLDMAN, Berthold. Traité de l'arbitrage commercial international. Paris: Litec, 1996. p. 395), estabelecendo o princípio segundo o qual o árbitro deve decidir sobre a sua própria competência. A partir deste último princípio é que se configura o chamado princípio da compétence-compétence.

${ }^{31}$ Não é o objetivo da presente tese tecer considerações a respeito de uma suposta diferença entre os termos "procedimento arbitral" e "processo arbitral", até porque tais diferenças em nada contribuirão para o deslinde do presente estudo. A essência do "procedimento" ou "processo arbitral", no final, é a mesma, e ambos os termos serão utilizados ao longo deste trabalho. Carlos Alberto Carmona prefere o termo "processo" a procedimento arbitral, pelas seguintes razões: "Notem que não falei em procedimento arbitral, mas sim em processo arbitral, porque minha visão é de perfeita equivalência entre arbitragem (mecanismo jurisdicional) e o processo estatal (mecanismo também jurisdicional): em outras palavras, o árbitro faz, efetivamente, o papel de juiz, fato e de direito, e por isso a própria natureza jurídica do instituto responde a esta ideia de jurisdicionalidade". CARMONA Carlos Alberto. O processo arbitral. Revista de Arbitragem e Mediação, São Paulo: RT, v. 1, n. 1, p. 22, jan.-abr. 2004. Para uma verificação aprofundada a respeito da utilização dos termos "processo arbitral" e procedimento arbitral", ver PARENTE, Eduardo de Albuquerque. Processo arbitral e sistema. 2010. Tese (Doutoramento) Faculdade de Direito da Universidade de São Paulo, São Paulo. No prelo; e FRANCO MONTORO, Marcos André. Flexibilidade do procedimento arbitral. 2010. Tese (Doutoramento) - Faculdade de Direito da Universidade de São Paulo, São Paulo. No prelo.

${ }^{32}$ Nesse sentido, v. PARENTE, Eduardo de Albuquerque. Processo arbitral e sistema. 2010. Tese (Doutoramento) - Faculdade de Direito da Universidade de São Paulo, São Paulo, p. 137. No prelo.

${ }^{33}$ Nesse sentido. v. CARPENTER, Luiz. F. Da prescrição. 3. ed. Rio de Janeiro: Nacional de Direito, 1958. p. 44.

${ }^{34}$ No que se refere à duração do prazo, a questão litigiosa poderia ser remetida à determinada lei específica que eventualmente contenha disposições acerca do prazo prescricional. É o caso, por exemplo, da Lei do Cheque (Lei n. ${ }^{\circ}$ 7.357, de 02.09.1985) que, em seu art. 59, dispõe que o prazo para a pretensão de execução do cheque prescreve em seis meses. Sem razão, portanto, aqueles que entendem que as pretensões arbitrais seriam imprescritíveis, como entende Fábio de Possídio Egashira: “A Lei 9.307/1996 
Ocorre que importantes questões a respeito da prescrição, de caráter operacional, como a forma da interrupção da prescrição ${ }^{35}$ e os efeitos da expiração do prazo prescricional, que são disciplinados no CPC, deixaram de ser contemplados na Lei n. $^{\circ}$ 9.307/1996. Talvez seja por isso que nunca se falou sobre prescrição no âmbito arbitral, eis que as atenções sempre se dirigiam ao processo judicial, este, sim, afeto à prescrição em virtude de norma expressa no art. 269, inciso IV, do CPC.

Não se está querendo afirmar aqui que as questões (mesmos as operacionais) a respeito da prescrição deveriam estar contempladas em uma lei processual, o que seria incongruente com o escopo da prescrição, mas apenas mostrar que, de acordo a própria lei material brasileira - o CCB -, as atenções voltavam-se apenas ao processo judicial, e nada a respeito da arbitragem. Exemplo disso é o art. 202, inciso I, do CCB, que determina que a prescrição se interrompe por meio de despacho do juiz, mesmo incompetente, que ordenar a citação, "se o interessado a promover no prazo e na forma da lei processual". A lei processual referida, obviamente, é o CPC.

A ausência de dispositivos específicos no CCB inerentes à prescrição visando o âmbito da arbitragem gera certa insegurança para aqueles que operam no âmbito arbitral. É certo que os prazos de prescrição variam conforme a pretensão de direito material que é invocada, e encontram-se dispostos nos arts. 205 e 206 do CCB, e se aplicarão à determinada controvérsia que for instaurada perante os árbitros, mas, ainda assim, faltam disposições que se coadunem com as peculiaridades da arbitragem. Um exemplo disso é a referida questão da interrupção da prescrição, tratada no CCB com expressa remissão à lei processual civil, cujos dispositivos, e não os princípios, são inaplicáveis ao procedimento arbitral. ${ }^{36}$

Da mesma forma que a lei processual brasileira disciplinou alguns dos mais importantes efeitos da prescrição - como a forma de interrupção da prescrição (citação

\footnotetext{
não estabelece prazo prescricional para a pretensão de instituição da arbitragem. Em princípio, o direito de provocar a instalação do Juízo Arbitral pode ser exercido a qualquer tempo". ESGASHIRA, Fábio de Possídio. Arbitragem e prescrição. Revista de Arbitragem e Mediação, São Paulo: RT, n. 8, p. 36, jan.mar. 2006.

${ }^{35}$ Fala-se aqui da disposição do art. 219 , caput e $\S 1$. $^{\circ}$, do CPC.

${ }^{36}$ Ver, nesse sentido, CARMONA, Carlos Alberto. Flexibilização do procedimento arbitral. Revista Brasileira de Arbitragem, São Paulo: Thomson-IOB, n. 24, p. 14, out.-nov.-dez. 2009.
} 
judicial válida), assim como o da expiração do prazo prescricional (resolução da lide com julgamento do mérito) -, a lei de arbitragem nacional veio desprovida de elementos que preservassem a segurança jurídica do processo arbitral, em razão dos efeitos da prescrição extintiva, de modo a garantir a estabilidade das relações jurídicas submetidas à arbitragem e promover a "paz social" da arbitragem.

Tais questões são típicas do âmbito da arbitragem interna. Como se verá ao longo da tese, de modo a não tornar "descabido" o procedimento arbitral, à arbitragem interna se impõe o direito interno, ${ }^{37}$ de modo que à arbitragem interna se aplicarão as regras constantes do CCB no que diz respeito à prescrição. No entanto, as lacunas acima elencadas devem ser preenchidas, e tal preenchimento requer extensa interpretação e mudança legislativa, não na Lei de Arbitragem, mas no âmbito do direito material.

Já em sede de arbitragem internacional os problemas que envolvem a prescrição são maiores. Diversidade de leis, diversidade de prazos, tratamento diverso da prescrição (direito substantivo versus direito processual), possibilidade de modificação convencional dos prazos prescricionais e o caráter de ordem pública da prescrição constituem elementos que conflitam com a ampla autonomia e com as peculiaridades que caracterizam a arbitragem internacional.

Diversidade de leis porque, em arbitragem internacional, existem partes litigantes, normalmente de diferentes nacionalidades. Há uma sede da arbitragem que pode não ser a do país de um dos litigantes. Há uma lei aplicável ao contrato litigioso que normalmente é a lei que se aplica ao mérito do litígio e que, da mesma forma, pode ser uma lei diversa da nacionalidade das partes ou do país sede da arbitragem.

Diversidade de tratamento acerca do caráter da prescrição, que é abordada sob diferentes ângulos, recebendo qualificações jurídicas diversas nos países que adotam o

\footnotetext{
${ }^{37}$ Tal questão será analisada ao longo da tese, demonstrando que a liberdade concedida pelo art. $2 .^{\circ}$ da Lei n. ${ }^{\circ}$ 9.307/1996, principalmente para a eleição de uma lei estrangeira em um procedimento arbitral interno, é absolutamente descabido. Nesse sentido v. CASELLA, Paulo Borba (Coord.). Arbitragem: entre a praxe internacional, integração no Mercosul e o direito brasileiro. Arbitragem: lei brasileira e praxe internacional. 2. ed. rev. e ampl. São Paulo: LTr, 1999. p. 500.
} 
sistema romano-germânico (qualificação material da prescrição) e aqueles que utilizam a common law (qualificação processual da prescrição). ${ }^{38}$

E não é só: diversidade de características inerentes à forma com a qual a prescrição é tratada. Por exemplo, enquanto em alguns países os prazos prescricionais são inalteráveis (Brasil e Itália, por exemplo) em outros a modificação convencional da prescrição é permitida (Alemanha e França, por exemplo). Em outro exemplo, determinados países entendem que a instauração da arbitragem é motivo de suspensão da prescrição, ao passo que em outras leis mesma hipótese seria de interrupção.

No entanto, alguns pontos comuns e primordiais ao tratamento da prescrição podem ser notados: a prescrição constitui matéria de exceção de direito material, é uma arma de defesa do devedor. Salvo regras isoladas e descabidas (por exemplo, a do art. $219, \S 5^{\circ}$, do CPC), a prescrição só entra em cena quando alegada pelo devedor, que a utiliza conforme a estratégia que reputar adequada. Sua existência se coaduna com a necessidade de não deixar perecer as provas que poderiam ser utilizadas pelo devedor para a contraposição de eventual pedido infundado e tardio ou mesmo de modo a evitar um "duplo pagamento" pelo devedor". Mundialmente, a prescrição existe para que as relações jurídicas, não importando a esfera em que elas se desenvolvem - judicial ou arbitral -, se estabilizem e, com isso, seja a paz social promovida.

É justamente com base nesses pontos comuns e de convergência demonstrados pelo direito comparado - corroborado por diplomas de reconhecimento e respeito no meio internacional ${ }^{40}$ - que um caminho pode ser traçado para que as questões que digam respeito à prescrição no âmbito da arbitragem internacional sejam tratadas de

\footnotetext{
${ }^{38}$ Como dizia Oscar Tenório, "Por sua natureza social e mesmo política, a prescrição é instituto que apresenta, em cada Estado, peculiaridades. Por isto, os prazos são variáveis nas diversas legislações do mundo [...]. A diversidade legislativa e a maneira por que se encara a prescrição são razões que justificam o estudo da matéria à luz do conflito de leis" (Direito internacional privado. 11. ed. rev. e atual. por Jacob Dolinger. Rio de Janeiro: Freitas Bastos, 1976. p. 216).

${ }^{39}$ Nesse sentido já dizia Alain Bénabent: “[...] la prescription a pour fonction d'éviter un double paiement lorsque la dette a été payée (ou comepensée) sans que le débiteur (souvent ses héritiers) puisse retrouver la trace de ce paiement" (Le chaos du droit de la prescription extinctive. Mélanges dédiés à Louis Boyer. Toulouse: Presses Universitaires de Toulouse, 1996. p. 127).

${ }^{40}$ Exemplo disso, como se verá ao longo da tese, é a Convenção sobre Prescrição em Matéria de Venda Internacional de Mercadorias, firmada em Nova York, em 14.06.1974, adotada pela United Nations Commisssion on International Trade Law (Uncitral) e os Princípios elaborados pela Unidroit (International Institute for de Unification of Private Law) em 2004, para o comércio internacional.
} 
forma harmônica e uniforme, sob a égide de uma única ordem jurídica, a "ordem jurídica arbitral".

Como se verá ao longo desta tese, o campo da arbitragem internacional é o campo da autonomia, o campo da liberdade, o campo apropriado para que os assuntos relativos ao comércio internacional sejam resolvidos. Na arbitragem internacional, não existe foro, ou, melhor dizendo, o foro é o mundo, nas palavras de Emmanuel Gaillard. $^{41}$ Mas o tempo é um elemento de caráter público, e, por mais que o seu decurso seja visto como um fator de desagregação, ${ }^{42}$ ele age no sentido de gerar paz nas relações jurídicas, eliminando aquelas pretensões tardiamente apresentadas. Como então conciliar essa ampla autonomia da arbitragem internacional com normas de interesse público que servem para dar estabilidade às relações jurídicas? Como conciliar essa autonomia com a diversidade de leis supostamente regentes da prescrição que podem surgir em uma arbitragem internacional?

E é justamente essa diversidade de tratamento em relação ao escopo da prescrição extintiva que justifica uma ampla investigação de seus efeitos na seara internacional e no campo do direito comparado, pois, a partir dessa análise, soluções podem ser almejadas para a arbitragem internacional.

O estudo que se pretende realizar nesta tese demonstrará que a prescrição extintiva, com toda a certeza, promove todos os seus efeitos em sede arbitral, ainda que não haja uma regulamentação específica para tanto. Mas uma regulamentação própria, sobretudo no âmbito internacional, seria salutar e bem-vinda, pois certamente tornaria mais sadio o desenvolvimento das relações jurídicas submetidas à arbitragem internacional. $^{43}$

\footnotetext{
41 Nesse sentido, v. GAILLARD, Emmanuel. Aspects philosophiques du droit de l'arbitrage international. Leiden/Boston: Les livres de poche de l'académie de droit international de l'Haye, Martinus Nijhoff Publishers, 2008. p. 47.

${ }^{42}$ Como entende, por exemplo, Paulo Borba Casella (Fundamentos do direito internacional pós-moderno. São Paulo: Quartier Latin, 2008. p. 738).

${ }^{43}$ Referência se faz aqui ao preâmbulo da Convenção de NY de 1974, ao considerar a importância da uniformização das regras sobre prescrição em matéria de venda internacional de mercadorias: "[...] Believing that the adoption of uniform rules governing the limitation period in the international sale of goods would facilitate the development of world trade [...]".
} 
Portanto, no âmbito do direito interno, no caso o brasileiro, o CCB dará os ditames para que a prescrição seja bem interpretada no âmbito da arbitragem. Seja na fase pré-arbitral, na fase arbitral ou na fase pós-arbitral, a prescrição promoverá todos os seus efeitos. Tão somente em relação a determinadas questões é que se procurará demonstrar que uma reforma legal geraria menos insegurança aos operadores da arbitragem no direito brasileiro, o que valeria também para as arbitragens internacionais em que a lei brasileira fizesse parte do regime aplicável ao mérito do litígio.

Já no âmbito internacional, em que o regime jurídico da prescrição pode estar sujeito a diversas leis, tal diversidade pode ser atenuada pela criação de regras uniformes sobre um regime de prescrição, ou, em uma hipótese mais próxima, de adesão às regras que já existem no meio internacional (Convenção de NY de 1974 ou Princípios Unidroit de 2004) estancando todas as dúvidas que poderiam surgir aos operadores da arbitragem internacional.

Para chegar ao ponto de uniformizar tais regras, existe um árduo caminho a ser percorrido. É preciso delimitar qual a real função da prescrição no âmbito internacional. Dar estabilidade às relações jurídicas? Dar estabilidade à empresa comercial? Preservar o direito de prova do prescribente, isto é, aquele adquire o direito da prescrição?

Mostrar-se-á que, diferentemente do âmbito interno, a prescrição em termos de direito internacional (o que vale para a arbitragem internacional) não é um instituto de ordem pública internacional. Regras de um país sobre prescrição, mesmo que diversas, podem ser aplicadas em outro país sem que haja ofensa à ordem pública. A prescrição em termos internacionais não é chocante ou perturbadora. É tão somente um instrumento de defesa criado pela lei, posto à disposição da parte que a aproveita. Esta última alega a prescrição apenas se for do seu interesse. Pode até mesmo pagar dívida prescrita.

Conquanto as diversas dúvidas e obscuridades que o instituto da prescrição apresenta na arbitragem possam ser resolvidas de uma só forma, que, como se verá ao longo desta tese, é desvinculando a prescrição de quaisquer leis eventualmente 
aplicáveis, à exceção da lei aplicável à substância do litígio, ${ }^{44}$ a diversidade de prazos e diferentes tratamentos acerca da prescrição não teria fim. Dessa forma, a tese procurará demonstrar que a resolução de tais problemas se atenuaria se todas as questões sobre prescrição, na esfera da arbitragem internacional, fossem remetidas a um só diploma. $\mathrm{O}$ objetivo aqui é pura e simplesmente tornar o procedimento arbitral leve, livre de interferências e dúbias interpretações, e, ao mesmo tempo, promover o que se poderia chamar de paz social na arbitragem internacional, resumida pela estabilidade das relações jurídicas comerciais.

Colocadas as premissas inerentes ao tema proposto, passa-se a anunciar o plano desta tese, que será dividida da seguinte forma:

Em uma primeira parte, será analisada a razão de ser do instituto da prescrição extintiva quando se está sob o escopo da jurisdição arbitral. Nessa parte, dois títulos serão abertos: o primeiro (Título I) tratará do âmbito de aplicabilidade da prescrição extintiva em sede arbitral, e dois capítulos serão dedicados a essa discussão: o primeiro (Capítulo 1) analisará o objeto e os aspectos da arbitragem interna e internacional e sua relação com o fator tempo. Tratado normalmente como uma questão flexível, o tempo ganha forma de rigidez quando o que se está em jogo é a prescrição. Por isso, o Capítulo 2 dedicar-se-á ao estudo do objeto e dos aspectos da prescrição extintiva no direito interno e internacional. Ao final desse capítulo, considerações conclusivas acerca do Título I serão tecidas. Ainda na primeira parte, mas já adentrando nos aspectos internacionais do tema proposto, será aberto o Título II, cuja discussão se voltará ao estudo do regime jurídico aplicável à prescrição extintiva na arbitragem. Para o exame dessa questão, dois capítulos serão abertos: o primeiro (Capítulo 1) será dedicado ao estudo da natureza jurídica e da qualificação da prescrição extintiva, respectivamente,

\footnotetext{
${ }^{44}$ Conforme se verificará na tese, a prescrição, em matéria internacional, constitui matéria substantiva e, caindo sobre o império da lei aplicável ao mérito da controvérsia, o tratamento apartado da matéria, segundo Luiz Olavo Baptista, não mereceria maiores considerações. Mas, ao final, o referido autor deixa evidente que a remissão única da prescrição à lex causae não seria um fator de promoção da "tranquilidade": "Para o efeito de evitar conflito de leis, a solução oferecida pelos países da civil law apresenta vantagens práticas. A lei escolhida para reger o contrato (e vimos atrás as regras relativas à escolha da lei ou à sua designação) também imperará sobre as questões relativas à prescrição e seus efeitos. Em razão disso, geralmente os juristas oriundos de países do sistema 'romano germâmico', como é o nosso país, não costumam preocupar-se com esse problema; a prescrição, como outras matérias substantivas, para eles, cai sob o império da lei aplicável, e não merece um tratamento apartado. É claro que só haverá tranquilidade quanto a esse aspecto se, além da lei aplicável, o foro for também o de um país de civil law". BAPTISTA, Luiz Olavo. Dos contratos internacionais: uma visão teórica e prática. São Paulo: Saraiva, 1994. p. 124-125.
} 
em sede de arbitragem interna e internacional. Em seguida, o Capítulo 2 analisará a questão relativa à determinação da lei aplicável à prescrição extintiva na arbitragem internacional. Assim como no Título I, o Título II também será objeto de uma conclusão, da mesma forma que haverá uma breve conclusão relativa à primeira parte, como um todo, da tese.

Na segunda parte da tese, o seu objeto se cingirá ao estudo dos efeitos gerados pela incidência da prescrição extintiva e à necessidade de sua regulamentação no âmbito da arbitragem interna (brasileira) e internacional. Assim como na primeira parte, dois grandes títulos serão abertos: o primeiro (Título I) analisará os efeitos gerados pela prescrição extintiva nas três fases da arbitragem. Por razões de cunho metodológico, no Capítulo 1 serão tratados os efeitos gerados pela prescrição nas fases pré-arbitral e arbitral, enquanto o Capítulo 2 se dedicará ao estudo dos efeitos da prescrição na fase pós-arbitral. Na sequência, uma conclusão será apresentada. O segundo (Título II) tentará responder ao seguinte questionamento: os efeitos gerados pela prescrição extintiva justificam a regulamentação da matéria em sede arbitral? A resposta a ser apresentada será dividida em dois capítulos: no primeiro (Capítulo 1) analisar-se-á como a questão se inseriria no plano interno (brasileiro), ao passo que no Capítulo 2, será indicada uma proposta para o plano internacional. Após tecer conclusões a respeito do Título II, uma conclusão relativa à segunda parte da tese será apresentada, sendo esta uma conclusão geral do trabalho realizado.

O anúncio do plano geral desta tese resta, portanto, assim definido:

Primeira parte - A razão de ser da prescrição extintiva na arbitragem interna e internacional.

Segunda parte - Os efeitos gerados pela prescrição extintiva e a necessidade de sua regulamentação no âmbito da arbitragem interna e internacional.

O estudo contemplará tanto a arbitragem interna quanto a internacional, tendo como base a visão a partir do direito brasileiro. 


\section{CONCLUSÃO DO TÍTULO I (PRIMEIRA PARTE)}

O objetivo da matéria tratada no Título I deste estudo foi estabelecer as premissas básicas dos institutos da arbitragem e da prescrição extintiva, nos planos interno e internacional. Tais premissas são fundamentais para discorrer acerca do regime jurídico aplicável à prescrição extintiva em sede arbitral.

As conclusões preliminares atingidas com este estudo demonstram que:

- O procedimento arbitral é mais do que um simples procedimento, é um meio processual idôneo capaz de realizar a tutela jurisdicional;

- Os direitos tutelados em arbitragem assimilam-se aos direitos subjetivos a uma prestação, e a sentença arbitral poderá adotar caráter condenatório;

- Apesar da flexibilidade da arbitragem, notadamente em relação ao fator tempo, a pretensão arbitral está sujeita aos efeitos do decurso do tempo, isto é, se não exercido o direito subjetivo de instauração de procedimento arbitral no período determinado pela lei aplicável à controvérsia, a demanda arbitral poderá sofrer os efeitos da prescrição extintiva;

- A prescrição extintiva, no direito brasileiro, fulmina a pretensão, restando em estado latente o direito perseguido, que não se extingue pela prescrição;

- Em matéria de direito comparado e de direito internacional, em geral, a prescrição extintiva é revestida de diferentes funções, e, por isso, quando perfaz o objeto de determinada controvérsia, deve ser previamente qualificada;

- O direito brasileiro é desprovido de regulamentação própria em relação à prescrição extintiva em matéria arbitral, tanto no direito interno quanto no direito internacional. 
Verificados, portanto, os objetivos e peculiaridades do instituto da arbitragem e da prescrição extintiva, e, levando-se em conta a mencionada lacuna de regulamentação da matéria no direito brasileiro, formulam-se as seguintes indagações: qual a necessidade de regulamentar a questão da prescrição na arbitragem? Seria imperioso, diante da jurisdição arbitral, formular regras que punissem a inércia daquele que sofreu a lesão, e que deveria valer-se da convenção de arbitragem para instaurar o competente procedimento arbitral?

No direito interno (arbitragem interna), a matéria repercutiria mais sobre as questões formais inerentes à prescrição - como forma de interrupção e suspensão -, eis que, por mais que haja opiniões isoladas da doutrina a respeito da regência de uma arbitragem interna por uma lei estrangeira, o que, como já verificado, é excessivo e descabido, existe uma praticidade (e razoabilidade) maior quando um procedimento arbitral interno, cujo fim é a prolação de uma sentença que, se condenatória, poderá, automaticamente, se tornar título executivo judicial, seja regido e controlado por disposições do próprio direito nacional. ${ }^{45}$

A questão toma rumo diferente quando se está diante do cenário internacional. Como no âmbito interno, poder-se-ia pensar na eventual regulamentação de questões formais e procedimentais acerca da prescrição extintiva. No entanto, a dificuldade maior aparecerá quando da determinação do regime jurídico aplicável à prescrição. O objetivo do direito internacional privado, como frisado anteriormente, é resolver conflitos de lei no espaço. O procedimento se dá, inicialmente, por meio da qualificação do problema, em matéria internacional, passando-se, em seguida, a determinar a lei aplicável à controvérsia.

No entanto, a prescrição extintiva, quando inserida no âmbito do conflito de leis no espaço, dá margem à discussão sobre a sua natureza jurídica, isto é, a sua qualificação - matéria substancial ou processual. Conquanto a existência de diplomas uniformes atenue os problemas relativos à interferência de outras leis sobre a prescrição (como é o caso da Convenção de NY de 1974 e dos Princípios Unidroit de 2004), mas

45 Como afirma Martim Della Valle, nas arbitragens internas, pode-se dizer que existe uma "ordem jurídica estatal de referência" (Da decisão por equidade na arbitragem comercial internacional. 2009. Tese (Doutoramento) - Faculdade de Direito da Universidade de São Paulo, São Paulo, p. 148. No prelo). 
sabendo-se que bem sempre essas regras são adotadas pelas partes, para que se possa determinar a lei aplicável à prescrição extintiva no contexto de uma arbitragem internacional revela-se imperioso estudar a prescrição à luz da teoria das qualificações, ou seja, definir a lei qualificadora da prescrição e, por fim, qualificar o instituto da prescrição. $^{46}$ Tal questão será minudentemente analisada no Título II desta primeira parte.

\footnotetext{
${ }^{46}$ Tomando-se como base o direito internacional privado brasileiro.
} 


\section{CONCLUSÃO DO TÍTULO II (PRIMEIRA PARTE)}

O objetivo da matéria tratada no Título II deste estudo foi detectar a natureza jurídica da prescrição extintiva em sede de arbitragem interna e, na seara internacional, qualificar o instituto da prescrição de modo a proceder à determinação da lei a ela aplicável.

\section{Assim sendo, verificou-se que, em sede de arbitragem interna:}

- As regras gerais sobre prescrição extintiva disposta no Código Civil se aplicam a todas arbitragens, com a ressalva de aplicabilidade de diploma especial à matéria de fundo que contenha disposições específicas sobre prazos prescricionais;

- A prescrição constitui questão de direito material, representando um dos pilares da ordem pública material. Portanto, se invocada a prescrição por quem a aproveita e se comprovado o escoamento do lapso prescricional, o tribunal arbitral deverá extinguir a demanda arbitral com resolução do mérito;

- A decretação ex officio da prescrição, conforme a nova redação do $§ 5 .^{\circ}$ do art. 219 do CPC, não se aplica às arbitragens internas: primeiro, porque os dispositivos do CPC são inaplicáveis à arbitragem; em segundo lugar porque a reforma processual que resultou na referida disposição visou unicamente ao desafogamento do Judiciário e ainda assim padece de verdadeira contradição em face do caráter de exceção de direito material do qual é revestido a prescrição.

No tocante à arbitragem internacional, ficou verificado que:

- Para se proceder à determinação da lei aplicável à prescrição extintiva é necessário passar pelo processo de qualificação do instituto da prescrição em razão do seu diverso tratamento nos sistemas da civil law e da common law; 
- Tradicionalmente, no âmbito do direito internacional privado, a lex fori é a competente para qualificar institutos jurídicos, como a prescrição;

- No entanto, como na arbitragem não existe foro, e a lex arbitri atua como forma de suporte ao procedimento arbitral (ou no máximo como lei competente para discussão judicial a respeito da sentença arbitral), a única "ordem jurídica de referência" para que se qualifique a prescrição extintiva é a lex causae ou a lei que for aplicável ao mérito da controvérsia submetida à arbitragem;

- Em sede de arbitragem internacional, sendo a lei aplicável ao mérito a lei brasileira, a prescrição extintiva qualificada com base na referida lei sempre será considerada questão de direito material;

- Qualificada a prescrição extintiva com base em determinado ordenamento jurídico, os árbitros passam a determinar a lei aplicável ao referido instituto;

- Conforme teoria do direito internacional privado, a prescrição extintiva é normalmente remetida à lex causae, não se enquadrando nas matérias inerentes à ordem pública internacional;

- O direito comparado, refletido em diplomas internacionais de peso, com força legal como a Convenção de NY de 1974, e com caráter de soft law, como é o caso dos Princípios Unidroit de 2004, demonstra que, no âmbito internacional, a prescrição extintiva é questão de mera exceção de direito material, posta à disposição de quem a aproveita e necessita utilizá-la;

- Seguindo a linha de entendimento acima, nas arbitragens internacionais (ao menos sob a égide da CCI), a prescrição extintiva é submetida à lei aplicável ao fundo da controvérsia, de escolha das partes;

- No caso de ausência de escolha pelas partes da lei aplicável ao fundo do litígio, a prescrição extintiva é submetida à lei que os árbitros reputarem adequada ao caso concreto. A determinação dos árbitros, nesse sentido, é promovida ou pela utilização de 
uma regra conflitual entre as diversas leis que envolvem o litígio, ou por meio do método da voie directe;

- No método da voie directe, tradicionalmente aceito pela comunidade internacional, os árbitros determinam que a prescrição extintiva seja regida pela lei que mais se aproxima do mérito do litígio, podendo ser a lei aplicável ao contrato firmado entre as partes, ao lugar que os negócios se desenvolveram ou mesmo, nos casos de responsabilidade extracontratual, à lei em que o ilícito ocorreu (lex loci delictis);

- Nas arbitragens decididas por equidade em direito interno, a prescrição causa barreira à decisão pelo sentimento de justiça, por constituir questão de ordem pública interna. No entanto, o limite para que não se derroguem as regras sobre prescrição vai até a sua consumação, isto é, se firmado termo de arbitragem após a consumação do prazo prescricional, presumir-se-á que houve renúncia da prescrição e, com isso, esta passa ser matéria disponível e, portanto, passível de derrogação pelo julgamento ex aequo et bono;

- As conclusões tiradas das arbitragens internas decididas por equidade não valem para as arbitragens internacionais. Apesar de a prática arbitral internacional demonstrar que há o descarte apenas da prescrição adquirida (sob argumento implícito de que, quando não adquirida, a prescrição seria questão de ordem pública), é preciso deixar claro que nas arbitragens internacionais decididas por equidade, ainda que a ordem pública internacional possa causar algum tipo de barreira, não seria essa barreira a prescrição. Se nas arbitragens de direito há uma grande aceitação das leis estrangeiras que disponham, no mérito, sobre a prescrição, assim deve ocorrer nas arbitragens por equidade, ainda mais pelo fato de estas não estarem conectadas a uma lei, e sim à consciência dos árbitros. 


\section{CONCLUSÃO DA PRIMEIRA PARTE}

A primeira parte desta tese procurou mostrar a razão de ser da prescrição extintiva em sede de arbitragem interna e internacional.

Ficou demonstrado que a prescrição extintiva é um instituto presente em diversas legislações, e, ainda que seja um instituto de direito material nos países de civil law e de direito processual nos países de common law, o objetivo da prescrição é proteger um devedor contra demandas tardias.

Importante destacar que, segundo as premissas estabelecidas nesta tese, na maioria dos ordenamentos internos, em que se inclui o direito brasileiro, a prescrição extintiva é considerada não apenas uma questão de direito material, mas um instituto que se enquadra no interesse público, na estabilidade das relações jurídicas. $O$ fim da prescrição extintiva no direito interno é, portanto, a manutenção da paz social.

Diferentemente, no plano internacional, sobretudo no âmbito das relações comerciais internacionais, a prescrição não se afigura como um instrumento de ordem pública. Sua utilização é colocada à disposição das partes, tendo como fim a estabilidade das relações jurídicas comerciais, protegendo a empresa devedora das demandas tardiamente propostas, em que as provas já desapareceram.

Tais premissas revelam notável importância para o desenvolvimento da segunda parte desta tese, em que se verificarão os efeitos diretos causados pela prescrição extintiva no âmbito da arbitragem interna e internacional, em todas as suas fases, desde a formação do ato interruptivo da prescrição até os seus efeitos na esfera pós-arbitral, quando novas questões acerca da prescrição extintiva poderão surgir.

É o que se propõe analisar na parte seguinte. 


\section{CONCLUSÃO DO TÍTULO I (SEGUNDA PARTE)}

O objetivo da matéria tratada no Título I desta segunda parte foi detectar os mais importantes efeitos causados pelo instituto da prescrição extintiva na arbitragem interna e internacional, em todas as fases do procedimento.

A prescrição extintiva é considerada um instituto cuja função é punir a inércia do titular de um direito violado pelo decurso do tempo. Isto é, a verdadeira e final função da prescrição é gerar a extinção da pretensão, resolver o mérito da demanda, como ocorre no direito brasileiro, ou simplesmente causar o impedimento do titular de exercer o seu direito de agir, como acontece em outros diplomas.

No entanto, determinados aspectos aqui chamados de "operacionais" da prescrição culminam por gerarem certos efeitos em um procedimento arbitral, o que vai desde a etapa que antecede a fase posterior da arbitragem, efeitos estes que, de alguma forma, inquietam os operadores da arbitragem.

É assim que, na fase pré-arbitral, o instituto da prescrição extintiva gera dúvidas sobre a forma e o exato momento em que o curso do prazo prescricional é interrompido, dúvidas acerca da possibilidade ou não da modificação convencional dos prazos prescricionais, e dúvidas a respeito da suspensividade ou não de um prazo prescricional. A análise detalhada dessas questões permitiu que se chegasse às seguintes conclusões:

- No direito brasileiro, não existe a certeza de que a instauração da arbitragem interrompe a prescrição. Ao menos que tal instauração se dê com o prazo prescricional em curso e com folga;

- Para que haja a certeza da concretização da interrupção da prescrição na arbitragem, segundo o direito brasileiro, notadamente nos casos em que o prazo está no limite, a única forma segura e com respaldo legal de interromper a prescrição é por intermédio do protesto judicial; 
- No direito comparado, a incerteza da questão atinge graus maiores na medida em que diversas legislações (leis materiais ou mesmo leis de arbitragem) promovem várias formas e modalidades de interrupção da prescrição;

- Essa incerteza é comprovada mediante a demonstração da prática da arbitragem. As sentenças CCI examinadas indicam que as formas de interrupção da prescrição são bastante variadas, e, na ausência de um denominador comum, em termos internacionais, em relação à matéria, a análise do ato interruptivo deve ser feita considerando o que consta dos autos e sempre atendendo às disposições da lei aplicável ao mérito da controvérsia;

- Ainda mais incerta é a questão relativa à modificação do prazo prescricional pelas partes. Tudo depende da lei que se aplica ao fundo do litígio, e, se esta permitir a modificação convencional do prazo, os árbitros julgarão conforme a previsão contratual. O problema é que nem todas as legislações permitem essa modificação, como é o caso da brasileira;

- No que tange à suspensão da prescrição, esta pode atuar na arbitragem, e não na interrupção. Alguns diplomas recentes e modernos possuem disposições específicas nesse sentido (direito alemão, Convenção de NY de 1974 e Princípios Unidroit de 2004), e, diante desse quadro, mais um item de incerteza se faz presente, na medida em que na suspensão da prescrição o prazo, o qual já tenha cessado, é aproveitado, diferentemente da interrupção, em que o prazo é rejuvenescido.

Por seu turno, na fase arbitral verificou-se que os efeitos acarretados pela prescrição se resumem basicamente na questão relativa à sua expiração. Os efeitos da expiração do prazo prescricional variam desde a extinção da demanda com julgamento de mérito (direito brasileiro) até o simples impedimento do direito de agir (Convenção de NY de 1974 e Princípios Unidroit de 2004). O que é certo e reconhecido no direito brasileiro e no direito comparado é que a prescrição extintiva constitui um meio de defesa do devedor, e os efeitos da expiração do prazo de prescrição somente se operam quando a exceção é invocada. O que significa que os efeitos da expiração do prazo prescricional se voltam apenas à pretensão, ao direito de agir na esfera arbitral, que resta 
extinto, mas o direito, o cerne da obrigação, permanece vivo, em estado latente, e poderá voltar a atuar mesmo que os efeitos da expiração do prazo tenham se operado.

Finalmente, no tocante à fase pós-arbitral, verificou-se mais um extenso leque de efeitos que a prescrição extintiva poderá causar. Conquanto a fase arbitral tenha o seu término com a prolação da sentença arbitral, ou dos "embargos arbitrais", a prescrição ressurge na fase pós-arbitral, normalmente na fase de execução da sentença. Portanto, constatou-se que:

- No direito brasileiro, a prescrição extintiva atua normalmente no que se refere às pretensões de execução da sentença arbitral proferida em arbitragem interna (Súmula 150 do STF);

- No que concerne ao processo de homologação de julgados forasteiros no Brasil, não incidem os efeitos da prescrição. Primeiro, porque a prescrição é questão de mérito da sentença levada ao juízo de delibação; segundo porque não há prazo extintivo de prescrição para o processo de reconhecimento junto ao STJ, e qualquer prazo extintivo que existisse nesse caso teria de ser decadencial, ante a caráter constitutivo da medida homologatória;

- Na fase de execução da sentença estrangeira no Brasil, a pretensão executória está sujeita à prescrição, cujo prazo deverá observar a lei aplicável ao mérito da controvérsia (normalmente a lei adotada pela sentença), isto é, a lex causae;

- Conquanto se entenda que à pretensão de execução de uma sentença estrangeira se aplique o prazo prescricional da lex causae, o juiz local, que procederá com a execução, aplicará as disposições de sua lex fori somente nos casos em que a disposição da lei estrangeira nada dispuser sobre a questão ou ofender a ordem pública do local da execução;

- A mesma prescrição extintiva que se opera desde a fase pré-arbitral e produz seus efeitos na fase arbitral também vale para a fase pós-arbitral. Isto é, se a sentença arbitral não for espontaneamente cumprida pelas partes, o litígio restará não resolvido, e o estado de incerteza permanecerá, de modo que o prazo de prescrição da pretensão de 
se executar o julgado arbitral volta a correr a partir do momento em que as partes são cientificadas da sentença.

Como se verificou, a prescrição extintiva gera efeitos de todas as espécies em sede arbitral.

Em sede de arbitragem interna, a prescrição não parece criar maiores obstáculos de interpretação, em razão da necessária submissão da arbitragem interna à lei interna. No entanto, há pontos que mereceriam alguma reforma legal, como o da interrupção da prescrição.

No campo internacional, se, por um lado, a observância da lex causae para tudo o que for inerente à prescrição extintiva pudesse ser considerada um exemplo de coerência nas relações jurídicas submetidas à arbitragem internacional, ainda assim persistiria um certo "caos" em razão da imensa diversidade de tratamento da prescrição, notadamente a diversidade de prazos.

Por tais razões, o título seguinte se dedicará ao estudo de uma possível regulamentação específica da prescrição em matéria de arbitragem, tanto no campo interno quanto no campo internacional. 


\section{CONCLUSÃO DO TÍTULO II (SEGUNDA PARTE)}

O Título II da segunda parte da tese foi consignado em uma pergunta: os diversos efeitos de cunho operacional gerados pela prescrição extintiva na arbitragem justificariam a regulamentação específica da matéria? A resposta é positiva.

O que se pôde notar, com absoluta clareza, é o fato de que a diversidade da prescrição extintiva, de uma forma global, é um elemento causador de incertezas e dificuldades. E, de certa forma, essas incertezas e dificuldades geram intranquilidade aos operadores da arbitragem. Como estabelecer um meio para que as incertezas e dificuldades cessem, ou sejam, no mínimo, atenuadas?

A começar pela arbitragem interna brasileira, verificou-se que ela fica atrelada ao ordenamento interno brasileiro. Trata-se uma relação jurídica interna que se resolve, consequentemente pelo direito interno. Estando a prescrição extintiva elencada no rol dos direitos materiais, pensa-se que algumas alterações a respeito de aspectos de ordem operacional da prescrição beneficiariam os operadores da arbitragem: em primeiro lugar, criando hipóteses claras de atos interruptivos da prescrição específicos para o meio arbitral. Em segundo lugar, suprimindo a regra da proibição de convencionar o prazo de prescrição, criando outra, apoiada no direito comparado. Trata-se de modificações que seriam de grande utilidade para os operadores da arbitragem, tanto interna tanto internacional, quando a lei brasileira se aplicar ao fundo da disputa.

Por seu turno, na arbitragem internacional, de um modo geral, verificou-se que o problema é mais denso do que no plano interno. As incertezas e dificuldades geradas pela prescrição extintiva são maiores, dada a diversidade de leis aplicáveis e ao diferente tratamento da prescrição pelos países de civil law e commom law. Por isso, pensa-se que a harmonização ou, se possível, a uniformização da matéria sobre prescrição no âmbito da arbitragem internacional mitigaria essas incertezas e dificuldades.

Enquanto a harmonização seria um processo mais leve, apoiado na jurisprudência arbitral e no sentido da existência de uma ordem jurídica arbitral, 
resumidos pela caracterização da prescrição como matéria de fundo ou de caráter transnacional, a uniformização seria mais forte, pois, com a criação de regras uniformes, o operador da arbitragem internacional teria uma maior facilidade de desvinculação dos direitos nacionais, tratando a prescrição extintiva e seus efeitos como matéria absolutamente separada, com influência específica nos procedimentos arbitrais.

O direito atual, em nível global, dispõe de dois instrumentos de caráter uniforme que regulam questões sobre prescrição extintiva com reflexos na arbitragem internacional. São eles a Convenção de NY de 1974 e os Princípios Unidroit de 2004. Enquanto o primeiro é um instrumento interestatal, mas de pouco sucesso, o segundo é não estatal e de largo sucesso e aceitação no meio da arbitragem internacional.

Como o elemento segurança jurídica justifica a existência da prescrição extintiva, pensa-se que uma regulamentação própria dessa matéria com reflexos específicos para arbitragem internacional colocaria um fim à diversidade da prescrição, causadora de incertezas e dificuldades para os operadores do direito. A elaboração de uma convenção sobre uniformização das regras sobre prescrição extintiva no contexto dos litígios submetidos à arbitragem internacional seria muito importante. No entanto, esse é um caminho difícil e longo de se traçar, de modo que, na atualidade, a adoção pelas partes, com base no princípio da autonomia da vontade, dos Princípios Unidroit de 2004, especialmente para regerem as questões sobre prescrição, é um primeiro passo para que haja um tratamento adequado da matéria, conferindo clareza aos operadores da arbitragem e segurança jurídica resumida pelo fim mediato da prescrição extintiva, que é o de dar estabilidade às relações jurídicas e concretizar a paz social. 


\section{CONCLUSÃO DA SEGUNDA PARTE}

A segunda parte da tese procurou especificar todos os efeitos que o instituto da prescrição extintiva pode causar no âmbito da arbitragem, seja ela interna, ou internacional. Para tanto, dividiu-se a discussão sobre os efeitos nas três fases da arbitragem: fase pré-arbitral, fase arbitral e fase pós-arbitral.

Verificou-se que nessas três fases a prescrição extintiva atua plenamente, com especial foco aos efeitos operacionais do instituto prescricional.

Se no âmbito do direito interno brasileiro algumas questões mereceriam reforma legal, no âmbito internacional uma verdadeira regulamentação específica da prescrição extintiva eliminaria dificuldades e incertezas, beneficiando os operadores da arbitragem internacional.

O que importa, ao final, é que a prescrição é uma só. Trata-se de uma regra reconhecida por todos os países civilizados, uma regra presente em todas as legislações e que possui fins, ainda que mediatos, que é a promoção da estabilidade das relações jurídicas, com a concretização da paz social. Em razão dessa presença maciça da prescrição nos ordenamentos internos há o reconhecimento de uma existência própria da prescrição no âmbito do direito internacional. Conquanto considerada como princípio geral do direito (para fins do direito internacional público), a prescrição vista pelo prisma internacional é mais flexível do que a do direito interno. Não constitui uma questão de ordem pública, e, em termos de direito comercial internacional, é utilizada para que dê estabilidade aos negócios tramitados naquela seara, protegendo o devedor das ações infundadas, cujas provas já pereceram, promovendo o giro das atividades comerciais.

No entanto, ainda que se acredite em uma existência própria da prescrição no âmbito do direito internacional e, pois, da arbitragem internacional, é preciso que haja uma regulamentação específica acerca da matéria, beneficiando os operadores da arbitragem internacional. Na ausência atual de uma regulamentação moderna, detalhada e de força cogente, recomenda-se que se utilizem as regras dispostas na Convenção de 
NY de 1974 ou, de uma forma mais abrangente, dos Princípios Unidroit de 2004, que, apesar constituírem instrumento não estatal, dispõem de um corpo de regras específicas e completas sobre prescrição extintiva e seus diversos efeitos. 


\section{REFERÊNCIAS BIBLIOGRÁFICAS}

\section{I - OBRAS GERAIS}

ABBUD, André de Albuquerque Cavalcanti. Homologação de sentenças arbitrais estrangeiras. São Paulo: Atlas, 2008.

ALEGRÍA, Hector. El Plazo en el Arbitraje Arbitraje Comercial y Arbitrage de Inversión. El Arbitraje en el Perú y el Mundo. Instituto Peruano de Arbitraje, Lima: Ediciones Magna, 2008. p. 281.

ALEXANDER, Gregory S. The application and Avoidance of Foreign Law in the Law of Conflicts. Northwestern. U.L. Rev., v. 70, p. 602, 1976.

ALMEIDA, João Alberto de. Processo arbitral. Belo Horizonte: Del Rey, 2002.

ALMEIDA, Ricardo Ramalho. Arbitragem comercial internacional e ordem pública. Rio de Janeiro: Renovar, 2005.

ÁLVARES, Adriano César da Silva. Manual da prescrição. Aspectos relevantes do Código Civil. São Paulo: Juarez de Oliveira, 2009.

ALVES, Vilson Rodrigues. Da prescrição e da decadência no novo Código Civil. 3. ed. Campinas: Servanda, 2006.

AMARAL, Francisco. Direito civil: introdução. 3. ed. Rio de Janeiro: Renovar, 2000.

AMORIM FILHO, Agnelo. Critério científico para distinguir a prescrição da decadência e para identificar as ações imprescritíveis. Revista dos Tribunais, São Paulo, v. 300, p. 7, 1960.

AMRANI-MEKKI, Soraya. Le temps et le procès civil. Tese, Paris I. Paris: Dalloz, 2002.

ANCEL, Bertrand. L'objet de la qualification. In: BÉGUIN, Jacques; DEHAUSSY, Jacques; JACQUET, Jean-Michel; MONÉGER, Françoise. Un siècle d'étude du droit international. Choix d'articles parus au Clunet (1874-2000). Paris: Litec, 2006. p. 303.

ANCEL, Marc. Utilidade e métodos do direito comparado: elementos de introdução geral ao estudo comparado dos direitos. Tradução de Sérgio José Porto. Porto Alegre: Fabris, 1980.

ANTUNES, Ana Filipa Morais. Prescrição e caducidade. Coimbra: Coimbra Editora, 2008. 
APRIGLIANO, Ricardo de Carvalho. A ordem pública no direito processual civil. 2010. Tese (Doutoramento) - Faculdade de Direito da Universidade de São Paulo, São Paulo. No prelo.

ARAGÃO, Paulo Cezar; ROSAS, Roberto. Comentários ao Código de Processo Civil. São Paulo: RT, 1975. v. 5.

ARMELIN, Donaldo. Prescrição e arbitragem. Revista de Arbitragem e Mediação, São Paulo: RT, n. 15, p. 65, out.-dez. 2007.

ARRUDA ALVIM. Da prescrição intercorrente. In: CIANCI, Mirna (Coord.). Prescrição no Código Civil: uma análise interdisciplinar. 2. ed. São Paulo: Saraiva, 2006. p. 27.

ASCHAUER, Cristian. La prescription des sentences arbitrales. Asa Bulletin, The Netherlands: Kluwer Law, v. 23, n. 4, p. 593, 2005.

BANIFATEMI, Yas (Ed.). Precedent in International Arbitration. IAI Series on International Arbitration, New York: Jurisnet, n. 5, 2008.

BAPTISTA, Luiz Olavo. Dos contratos internacionais: uma visão teórica e prática. São Paulo: Saraiva, 1994.

BARBOSA MOREIRA, José Carlos. O novo Código Civil e o direito processual. Revista Forense, Rio de Janeiro, v. 364, p. 186, 2002.

BARROS, Octávio Fragata M. de. Reflexões acerca dos efeitos infringentes dos embargos arbitrais. Revista Brasileira de Arbitragem, Porto Alegre: Thomson-IOB, ano II, n. 9, p. 62, 2006.

BARTIN, Etienne. Principes de droit international privé. Paris: Éditions DomatMontchrestien, 1930.

BASSO, Maristela. Procedimento arbitral atual: necessidade de um diálogo de reforma?. Arbitragem: estudos em homenagem ao Prof. Guido Fernando da Silva Soares (in memoriam). São Paulo: Atlas, 2007. p. 7.

BATALHA, Wilson de Souza Campos. Tratado elementar de direito internacional privado: parte geral. São Paulo: RT, 1977. v. 1.

- Tratado de direito internacional privado: parte especial. 2. ed. rev. e aum. São Paulo: RT, 1977. v. 2.

BATIFFOL, Henri. Contrats et conventions. Répertoire Dalloz de droit intenational privé, n. 9, p. 379. 
—_. La quatorzième session de la Conférence de La Haye de droit international privé. Revue critique de droit international privé, Paris: Librarie du Recueil Sirey, p. $231,1981$.

—. Nota sobre a decisão "Silvia", Corte de Cassação Francesa, 25 jun. 1957. In: ANCEL, Bertrand; LEQUETTE, Yves. Les grands arrêts de la jurisprudence française de droit international privé. 5. ed. Paris: Dalloz, 2006. p. 264.

BAUDRY-LACANTINERIE, G.; TISSIER, A. De La prescription. 4. ed. Paris: Librarie du Recueil Sirey, 1924.

BEHAR-TOUCHAIS, Martine. Foisonnement des délais. Les désordres de La prescription. Textes réunis par Patrick Courbe. Rouen: Publications de l'Université de Rouen avec le concours du Centre de recherche en droit des activités professionnelles, 2000. p. 14.

BELTRAMO, Mario; LONGO, Giovanni E.; MERRYMAN, John H. The Italian Civil Code and Complementary Legislation. New York: Oceana Publications, 2003.

BÉNABENT, Alain. Le chaos du droit de la prescription extinctive. Mélanges dédiés à Louis Boyer. Toulouse: Presses Universitaires de Toulouse, 1996, p. 123.

BERGER, Klaus Peter. International Economic Arbitration. The Hague: Kluwer Law International, 1993.

- The Creeping Codification of the New Lex Mercatoria. The Netherlands: Kluwer Law International, 2010.

- The German Arbitration Law of 1998: First Experiences. Law of International Business and Disoute Settlement in the $21^{\text {st }}$ Century. Heymann: Liver Amicorum KarlHeinz Bockstiegel, 2001. p. 31.

BERNARDINI, Piero. L'arbitrage en Italie après la recente reforme. Revue de l'arbitrage, Paris: Comité français de l'arbitrage, n. 3, p. 479, 1994.

- Limitation Periods. ICC International Court of Arbitration Bulletin (Special Supplement - Unidroit Principles: New Developments and Applications), Paris: ICC Publications, p. 43, 2005.

BETTO, Jean-Georges. Nota sobre a decisão proferida pela Corte de Apelações de Paris (1. ${ }^{a}$ Ch. Civ) em 28.11.2002. Revue de l'arbitrage Paris: Comité français de l'arbitrage, n. 4, p. 1360, 2003.

BEVILÁQUA, Clóvis. Princípios elementares de direito internacional privado. Rio de Janeiro: Editora Rio, 1906. p. 13. Edição histórica. 
—. Teoria geral do direito civil. 7. ed. Rio de Janeiro: Editora Paulo de Azevedo, 1955.

BOCKSTIEGEL, Karl-Heinz. Presenting evidence in international arbitration. ICSID Review: Foreign Investment Law Journal, Washington, v. 16, n. 1, p. 1-9, 2001.

- Public policy as a limit to arbitration and its enforcement. Revista de Arbitragem e Mediação, São Paulo: RT, v. 21, p. 163, 2009.

BOISSÉSON, Matthieu de. Le droit français de l'arbitrage interne et international. Paris: GLN éditions, 1990.

BOLARD, Georges. Les principes directeurs du procès arbitral. Revue de l'Arbitrage, Paris: Comité Français de l'Arbitrage, n. 3, p. 511, 2004.

BONNEL, Michael Joachim. An International Restatement of Contractual Law: The Unidroit Principles of International Commercial Contracts. New York: Transnational Publishers, 2005.

- Limitation Periods. Towards a European Civil Code. $3^{\text {rd }}$ Fully Revised Expanded Edition. The Hague: Kluwer Law International, 2004. p. 521.

BORN, Gary B. International Commercial Arbitration in the United States. Comentary and Materials. The Netherlands: Kluwer, 1994.

- International Commercial Arbitration. The Netherlands: Kluwer Law International, 2009. v. 2.

BRAGHETTA, Adriana. A escolha da sede da arbitragem. Revista do Advogado, São Paulo: AASP, ano XXVI, p. 7, set. 2006.

—. A importância da sede da arbitragem: visão a partir do Brasil. Rio de Janeiro: Renovar, 2010.

BRUNNER, Cristoph. Force Majeure and Hardship Under General Contract Principles. Exemption for non-performance in international arbitration. The Netherlands: Kluwer Law International, 2009.

BRUSCHI, Marc. La prescription en droit de la responsabilité civile. Paris: Economica, 1997.

BUCHER, Andreas. L'ordre public et le but social des lois en droit international privé. Recueil des cours de l'académie de droit international de La Haye, t. 239, p. 26, 1993.

BULHÕES, A. Nabor A.; JACCOUD, D’Alembert J. Contestação de pedido de homologação de sentença arbitral estrangeira - Ausência de motivação da sentença homologanda. Prescrição da pretensão arbitrada. Revista de Arbitragem e Mediação, São Paulo: RT, v. 2, p. 325, maio-ago. 2004. 
BUZAID, Alfredo. A ação declaratória no direito brasileiro. São Paulo: Saraiva, 1943.

CAHALI, Yussef Said. Prescrição e decadência. São Paulo: RT, 2008.

CAIVANO, Roque J. Arbitraje. Su eficácia como sistema alternatifo de reslución de conflictos. Buenos Aires: Ad Hoc, 1993.

CÂMARA, Alexandre Freitas. Arbitragem: Lei n. ${ }^{\circ}$ 9.307/96. 5. ed. rev., ampl. e atual. Rio de Janeiro: Lumen Juris, 2009.

CÂMARA LEAL, Antonio Luís da. Da prescrição e da decadência. 2. ed. atual. por José de Aguiar Dias. Rio de Janeiro: Forense, 1959.

—. 3. ed. atual. por José de Aguiar Dias. Rio de Janeiro: Forense, 1978.

CARABIBER, Charles. L'arbitrage international de droit privé. Recueil des cours de l'académie de droit international de La Haye, v. 99, p. 150, 1960.

CARBONNIER, Jean. Notes sur la prescription extintctive. RTD civ., Paris: Sirey, p. $175,1952$.

CARIO, Robert. Les modifications conventionelles de la prescription extinctive. Petites Affiches, Paris: Lextenso éditions, n. 133, p. 9, 6 nov. 1998.

CARMONA, Carlos Alberto. A arbitragem no processo civil brasileiro. São Paulo: Malheiros, 1993.

—. Arbitragem e processo: um comentário à Lei 9.307/96. 2. ed. rev., atual. e ampl. São Paulo: Atlas, 2004.

—. 3. ed. São Paulo: Atlas, 2009.

—. Ensaio sobre a sentença arbitral parcial. Revista Brasileira de Arbitragem, Porto Alegre: Thomson-IOB, ano IV, n. 18, p. 7, 2008.

- Flexibilização do procedimento arbitral. Revista Brasileira de Arbitragem, São Paulo: Thomson-IOB, n. 24, p. 7, out.-nov.-dez. 2009.

- O processo arbitral. Revista de Arbitragem e Mediação, São Paulo: RT, v. 1, n. 1, p. 21, jan.-abr. 2004.

CARNEIRO, Paulo Cezar Pinheiro. Aspectos processuais da nova Lei de Arbitragem. In: CASELLA Paulo Borba (Coord.). Arbitragem: lei brasileira e praxe internacional. 2. ed. rev. e ampl. São Paulo: LTr, 1999. p. 291.

CARNELUTTI, Francesco. Sistema di diritto processuale civile. Pádua: Cedam, 1936. v. 1 .

CARPENTER, Luiz. F. Da prescrição. 3. ed. Rio de Janeiro: Nacional de Direito, 1958.

CARREIRA ALVIM, J.E. Direito arbitral. 3. ed. Rio de Janeiro: Forense, 2007. 
CARVALHO SANTOS, J.M. Código Civil brasileiro interpretado. 7. ed. Rio de Janeiro: Freitas Bastos, 1956.

CASELLA, Paulo Borba. A ordem pública e a execução de cartas rogatórias no Brasil. Revista de Faculdade de Direito USP, São Paulo: FDUSP, v. 98, p. 563, 2003.

—. Arbitragem internacional e boa-fé das partes contratantes. Revista dos Tribunais, São Paulo: RT, v. 668, p. 239, 1991.

(Coord.). Arbitragem: entre a praxe internacional, integração no Mercosul e o direito brasileiro. Arbitragem: lei brasileira e praxe internacional. 2. ed. rev. e ampl. São Paulo: LTr, 1999. p. 497.

—. Fundamentos do direito internacional pós-moderno. São Paulo: Quartier Latin, 2008.

—. Modalidades de harmonização, unificação e uniformização do direito - o Brasil e as Convenções Interamericanas de Direito Internacional Privado. In: — ; ARAÚJO, Nádia de (Coord.). Integração jurídica interamericana: as Convenções Interamericanas de Direito Internacional Privado (Cidips) e o direito brasileiro. São Paulo: LTr, 1998. p. 77.

CASTRO, Amílcar de. Direito internacional privado. 6. ed. Rio de Janeiro: Forense, 2008.

CHIOVENDA, Giuseppe. Instituições de direito processual civil. Tradução da 2. ${ }^{a}$ edição italiana por J. Guimarães Menegale. São Paulo: Livraria Acadêmica Saraiva, 1942.

CIANCI, Mirna. Do interesse na ação de protesto interruptivo da prescrição. In:

- (Coord.). Prescrição no Código Civil: uma análise interdisciplinar. 2. ed. São Paulo: Saraiva, 2006. p. 374.

CIMMA, Maria Rosa. Prescrizione e Decadenza. Digesto. 4. ed. Torino: UTET, v. 14, 1996.

CINTRA, Antonio Carlos de Araújo; GRINOVER, Ada Pellegrini; DINAMARCO, Cândido Rangel. Teoria geral do processo. São Paulo: Malheiros, 1992.

COAGUILA, Carlos Alberto Soto. Comentarios a la Ley General de Arbitraje des Peru. Arbitraje Comercial y Arbitrage de Inversión. El Arbitraje en el Perú y el Mundo. Instituto Peruano de Arbitraje. Lima: Ediciones Magna, 2008. p. 3.

—. Nueva Ley Peruana de Arbitraje. Lima: Instituto Peruano de Arbitrage - IPA, p. 3. Disponível em: <www.peruarbitraje.com>. Acesso em: 29 nov. 2010. 
COLLINS, Lawrence Antony; McCLEAN, JD; MORSE, CGJ. Dicey and Morris on the Conflict of Laws. 9. ed. Londres: Sweet \& Maxwell, 1993.

CONFÉRENCES des Nations Unies sur la prescription en matière de vente internationale d'objets mobiliers corporels. Documents officiels. New York: Nations Unies, 1975.

CONSTANTINESCO, Leontin-Jean. Tratado de direito comparado: introdução ao direito comparado. Edição brasileira organizada por Maria Cristina De Cicco. Rio de Janeiro: Renovar, 1998.

COSTA, José Augusto Fontoura. Normas de direito internacional. Aplicação uniforme do direito uniforme. São Paulo: Atlas, 2000.

—. Sobre luzes e sombras: arbitragem. Revista CEJ, Brasília, ano XIV, n. 48, p. $110,2010$.

COSTA, Nilton César Antunes da. Poderes do árbitro: de acordo do com a Lei 9.307/96. São Paulo: RT, 2002.

COURBE, Patrick. La presctiption en droit international privé. Les désordres de La prescription. Textes réunis par Patrick Courbe. Rouen: Publications de l'Université de Rouen avec le concours du Centre de recherche em droit des activités professionnelles, 2000.

CRUZ E TUCCI, José Rogério. Tempo e processo. São Paulo: RT, 1997.

DANTAS, Santiago. Prescrição e decadência. Programa de direito civil. Aulas proferidas na Faculdade Nacional de Direito. (1942-1945). Rio de Janeiro: Ed. Rio, 1977. p. 395.

DAVID, Réné. L'arbitrage dans le commerce international. Paris: Economica, 1982.

—. Os grandes sistemas do direito contemporâneo. Tradução de Hermínio A. Carvalho. São Paulo: Martins Fontes, 2002

—; BRIERLEY, John E.C. Major Legal Systems in the World Today. An Introduction to the Comparative Study of Law. Londres: Stevens \& Sons, 1985.

DELLA VALLE, Martim. Considerações sobre os pressupostos processuais em arbitragens. Revista Brasileira de Arbitragem, Porto Alegre: Thomson-IOB, n. 12, p. 7, out.-nov.-dez. 2006.

—. Da decisão por equidade na arbitragem comercial internacional. 2009. Tese (Doutoramento) - Faculdade de Direito da Universidade de São Paulo, São Paulo. No prelo. 
DERAINS, Yves. Les normes d'application immmédiate dans la jurisprudence arbitrale internationale. Le droit des relations économiques internationals: Études offertes à Berthold Goldman. Paris: Litec, 1983. p. 42.

-; SCHWARTZ. A Guide to the New ICC Rules of Arbitration. The Hague: Kluwer Law International, 1998.

DESDEVISES, Yvon. Demande en justice. Paris: Jurisclasseur, 1997. fascicule 126-6, p. 10.

DIDIER JR., Freddie. Aspectos processuais da prescrição: conhecimento ex officio e alegação em qualquer fase do procedimento. In: CIANCI, Mirna (Coord.). Prescrição no Código Civil: uma análise interdisciplinar. 2. ed. São Paulo: Saraiva, 2006. p. 59.

DIMOLITSA, Antonias. Autonomie et Kompetenz-Kompetenz. Revue de l'Arbitrage, Paris: Comité français de l'arbitrage, n. 2, p. 320, 1998.

DINIZ, Maria Helena. Curso de direito civil brasileiro. São Paulo: Saraiva, 1982. v. 1.

DOLINGER, Jacob. A evolução da ordem pública no direito internacional privado. 1979. Tese (Cátedra) - Universidade do Estado do Rio de Janeiro, Rio de Janeiro.

A ordem pública internacional em seus diversos patamares. Revista dos Tribunais, São Paulo, v. 828, p. 33, out. 2004.

—. Aplicação, prova e interpretação do direito estrangeiro: um estudo comparado de direito internacional privado. Revista de Direito Renovar, Rio de Janeiro: Renovar, v. 5, p. 57, maio-ago. 1996.

- Direito internacional privado (parte especial) - direito civil internacional: contratos e obrigações no direito internacional privado. Rio de Janeiro: Renovar, 2007.v. 2.

. Direito internacional privado: parte geral. 9. ed. atual. Rio de Janeiro: Renovar, 2008. p. 299-300.

- Evolution of Principles for Resolving Conflicts in the Field of Contracts and Torts. Recueil des cours de l'académie de droit international de La Haye, t. 283, p. 187, 2000 .

—. Ordem pública - Prescrição - Direito comparado. Revista de Direito Administrativo, Rio de Janeiro: Renovar, v. 226, p. 352, out.-dez. 2001.

—; TIBÚRCIO, Carmem. The Forum Law Rule in International Litigation Which Procedural Law Governs Proceedings to be Performed in Foreign Jurisdictions: Lex Fori or Lex Diligentiae?. Texas International Law Review, v. 33. n. 3, p. 425, Summer 1998. 
DRAHOZAL, Cristopher R.; NAIMARK, Richard W. Towards a Science of International Arbitration. The Hague: Kluwer Law International, 2005. p. 72. (Collected Empirical Research.)

EISEMANN, Frédéric. La lex fori de l'arbitrage commercial international. Travaux du Comitê français de droit international privé. Paris: Dalloz, 1977. p. 189.

ESGASHIRA, Fábio de Possídio. Arbitragem e prescrição. Revista de Arbitragem e Mediação, São Paulo: RT, n. 8, p. 36, jan.-mar. 2006.

FADLALLAH, Ibrahim. L'ordre public dans les sentences arbitrales. Recueil des cours de l'académie de droit international de La Haye, t. 249, p. 417, 1994.

FAUVARQUE-COSSON, Bénédicte. Aspects de droit comparé de la prescription. Les désordres de La prescription. Textes réunis par Patrick Courbe. Rouen: Publications de l'Université de Rouen avec le concours du Centre de recherche en droit des activités professionnelles, 2000. p. 44.

—. Development of Comparative Law in France. In: REIMANN, Mathias; ZIMMERMANN, Reinhard (Ed.). The Oxford Handbook of Comparative Law. Oxford: Oxford University Press, 2008. p. 38.

FERNANDES, Marcus Vinícius Tenorio da Costa. Anulação da sentença arbitral. São Paulo: Atlas, 2007.

FIGUEIRA JÚNIOR, Joel Dias. Arbitragem, jurisdição e execução. 2. ed. São Paulo: RT, 1999.

FIUZA, Cézar. Teoria geral da arbitragem. Belo Horizonte: Del Rey, 1995.

FOUCHARD, Philippe. La coopération du Président du Tribunal de Grande Instance à l'Arbitrage. Phlippe Fouchard: Écrits - Droit de l'arbitrage e droit du commerce international. Paris: Comitê français de l'arbitrage, 2007. p. 5.

- La portée internationale de l'annulation de la sentence dans son pays d'origine. Revue de L'Arbitrage, Paris: Comité Français de l'Arbitrage, p. 329. 1997.

—. Quand un arbitrage est-il international?. Phlippe Fouchard: Écrits - Droit de l'arbitrage e droit du commerce international. Paris: Comitê français de l'arbitrage, 2007. p. 251.

—. Suggestions pour accroître l'efficacité international des sentences arbitrales. Revue de l'arbitrage, Paris: Comité français de l'arbitrage, n. 4. p. 653, 1998.

-; GAILLARD, Emmanuel; GOLDMAN, Berthold. International Commercial Arbitration. Edited by Emmanuel Gaillard and John Savage. The Hague: Kluwer Law International, 1999. 
- $\quad-\quad-$ Traité de l'arbitrage commercial international. Paris: Litec, 1996.

FRANCO MONTORO, Marcos André. Flexibilidade do procedimento arbitral. 2010. Tese (Doutoramento) - Faculdade de Direito da Universidade de São Paulo, São Paulo. No prelo.

FRICK, Joachim G. Arbitration and Complex International Contracts. The Hague: Kluwer Law International, 2001.

GAILLARD, Emmanuel. Aspects philosophiques du droit de l'arbitrage international. Leiden/Boston: Les livres de poche de l'académie de droit international de l'Haye, Martinus Nijhoff Publishers, 2008.

—. Comentário à decisão “Sonidep”. Revue de l'arbitrage, p. 92, 1995.

—. La distiction des príncipes généraux du droit et des usages du commerce international. Études offertes à Pierre Bellet. Paris: Litec, 1991. p. 203.

—. L'interférence des juridictions du siège dans le déroulement de l'arbitrage. Liber Amicorum Claude Reymond: Autour de l'Arbitrage - Mélanges Offerts à Claude Reymond. Paris: Litec, 2004. p. 87.

- The Use of Comparative Law in International Commercial Arbitration. ICCA Series n. 4. Arbitration in Settlement of International Disputes Involving The Far Esat and Arbitration Combined Transportation. General Editor Pieter Sanders. The Hague: Kluwer Law, 1989. p. 283.

—. Thirty Years of Lex Mercatoria: Towards the Discriminating Application of Transnational Rules. ICCA Congress Series 1994. Planning Efficient Arbitration Proceedings: the Law Applicable in International Arbitration. The Hague: Kluwer Law International, 1996. p. 570.

GAMA JR., Lauro. Contratos internacionais à luz dos Princípios do Undroit 2004: soft law, arbitragem e jurisdição. Rio de Janeiro: Renovar, 2006.

- Os Princípios do Unidroit relativos aos contratos do comércio internacional 2004 e o direito brasileiro: convergências e possibilidades. Revista de Arbitragem e Mediação, São Paulo: RT, n. 8, p. 51-52, jan.-mar. 2006.

GASPAR, Renata Alvares. Reconhecimento de sentenças arbitrais estrangeiras no Brasil. São Paulo: Atlas, 2009.

GLENDON, Mary Ann; GORDON, Michael Wallace; OSAKWE, Cristopher. Comparative Legal Traditions. Saint Paul: West Publishing, 1985. 
GOLDMAN, Berthold. La volonté des parties et le rôle de l'arbitre dans l'arbitrage international. Revue de l'Arbitrage, Paris: Comité Français de l'Arbitrage, p. 469, 1981.

—. Les conflits des lois en matière d'arbitrage international de droit privé. Recueil des cours de l'académie de droit international de La Haye, t. 109, v. 2, p. 351, 1963

—. Régles de conflit, règle d'application immédiate et règles matérielles dans l'arbitrage commercial international. Travaux du Comité français de droit international privé (1966-1969). Paris: Dalloz, 1970. p. 119.

GOLDSTEIN, Gérald. L'experience canadienne en matière d'uniformisation, d'harmonisation et de coordination de droits. Revue Juridique Thémis, Montreal: Les éditions Thémis, v. 32, p. 235, 1998.

GOMES, Orlando. Introdução ao direito civil. 11. ed. Rio de Janeiro: Forense, 1995. v. 1.

GONÇALVES, Eduardo Damião. A prática do STJ na homologação de sentenças arbitrais estrangeiras. Arbitragem doméstica e internacional: estudos em homenagem ao Prof. Theóphilo de Azeredo Santos. Rio de Janeiro: Forense, 2008, p. 125.

Arbitrabilidade objetiva. 2008. Tese (Doutoramento) - Faculdade de Direito da Universidade de São Paulo, São Paulo. No prelo.

GONÇALVES NETO, Francisco. Arbitragem e prescrição. Revista LTr: Suplemento Trabalhista, São Paulo: LTr, v. 38, fascículo n. 117, p. 535, 2002.

GONZALEZ, Florian. La responsabilité délictuelle dans les sentences arbitrales de la Chambre de commerce internationale. Bulletin de la cour internationale de la CCI, Paris: ICC Publications, v. 13, n. 2, p. 41, 2. ${ }^{\circ}$ sem. 2002.

GOPALAN, Sandeeb. Transnational Commercial Law. Oxford: Oxford University Press, 2004.

GORDLEY, James. Comparative Legal Research: Its Function in the Development of Harmonized Law. The American Journal of Comparative Law (AJCL), v. 43, n. 4, p. $563,1995$.

GRANDE, Elisabetta. Development of Comparative Law in Italy. In: REIMANN, Mathias; ZIMMERMANN, Reinhard (Ed.). The Oxford Handbook of Comparative Law. Oxford: Oxford University Press, 2008. p. 108.

GRECO, Leonardo. Instituições de processo civil: introdução ao direito processual civil. Rio de Janeiro: Forense, 2009. v. 1.

GUERREIRO, José Alexandre Tavares. Fundamentos da arbitragem do comércio internacional. São Paulo: Saraiva, 1993. 
GUERRERO, Luís Fernando. Convenção de arbitragem e processo arbitral. São Paulo: Atlas, 2009.

GUIDE to National Rules of Procedure for Recognition and Enforcement of New Convention Awards. Bulletin de la Cour international d'arbitrage de la CCI, Supplément Spécial. Paris: ICC Publications, 2008.

HAGE-CHANINE, Fayez. La prescription extintive en droit international privé. Tradução de Paulo Borba Casella. Recueil des cours de l'académie de droit international de La Haye, t. 255, p. 231, 1995.

HAMMOND, Steven A. Making the case in international arbitration: a common law orientation to the marshalling and presentation of evidence. Revista de Arbitragem $e$ Mediação, São Paulo: RT, v. 5, n. 16, p. 171, jan.-mar. 2008.

HAY, Peter. An Introduction to U.S. Law. $2^{\text {nd }}$ ed. USA: Butterworth Legal Publishers, 1991.

HIRSCH, Alain. The Place of Arbitration and the Lex Arbitri. The Arbitration Journal, Nova York: American Arbitration Association, v. 34, n. 3, p. 43, 1979.

HÓBER, Kaj. Essays on International Arbitration. New York: Jurisnet, 2006.

HORSMANS, Guy. L'arbitrage et la Crise. Palestra de encerramento proferida no IX Congresso Internacional de Arbitragem - CBAr. Belo Horizonte, 20 out. 2009.

INSTITUTO de Direito Internacional - La prescription libératoire en droit international public. Institut de droit international, Session de La Haye (1925) in Mélanges - Droit International - 1910-1926. Faculté de droit de Paris, 1925, p. 17.

JARROSSON, Charles. La notion d'arbitrage. Paris: Bibliothèque de droit privé, 1987.

—. Qui tiens les rênes de l'arbitrage? Volonté des parties et autorité de l'arbitre. Revue de L'Arbitrage, p. 601, 1999.

—. Réflexions sur l'imperium. Études offertes à Pierre Bellet. Paris: Litec, p. 268.

JOLIVET, Emmanuel. Comentário sobre a sentença parcial proferida no caso CCI $\mathrm{n}^{\circ}$ 7.375 de 1996. Les cahiers de l'arbitrage. Paris: Gazette du palais, p. 255-256, jul. 2002.

- La question de la prescription extinctive dans l'arbitrage CCI. Les cahiers de l'arbitrage, Paris: Gazette du Palais, v. 2, p. 235, jul. 2004. 
—. Nota sobre a Sentença final proferida no caso CCI n. ${ }^{\circ} 6.864$ de 1994. Cahiers de l'arbitrage, Paris: Pedone, v. 4, p. 355, 2008.

—. Nota sobre a Sentença final proferida no caso CCI n. ${ }^{\circ} 8.826$ de 1997. Cahiers de l'arbitrage. Paris: Pedone, 2008. v. 4, p. 380.

KANAYAMA, Naoki. Extinctive Prescription on the Limitation of Actions. Edition of Ewoud H. Hondius. The Hague: Kluwer Law International, 1995.

KASSIS, Antoine. La reforme du droit de l'arbitrage international: Réflexions sur le texte proposé par le Comité français de l'arbitrage. Paris: L'Harmattan, 2008.

—. L'autonomie de l'arbitrage commercial international: le droit français en question. Paris: L'Harmattan, 2005.

KAUFMANN-KOHLER, Gabrielle. Qui contrôle l'arbitrage? Autonomie des parties, pouvoir des arbitres et principe d'efficacité. Liber Amicorum Claude Reymond: Autour de l'Arbitrage - Mélanges Offerts à Claude Reymond. Paris: Litec, 2004. p. 153-165.

KESSEDJIAN, Catherine. Principe de la contradiction et arbitrage. Revue de l'arbitrage, Paris: Comité français de l'arbitrage, n. 3. p. 381, 1995.

—. Transnational Public Policy. ICCA Series n. 13. International Arbitration 2006: back to basics? The Hague: Kluwer Law International, 2007. p. 857.

KIFFER, Laurence. L'amiable composition et l'arbitrage CCI. Bulletin de la Cour international d'arbitrage de la CCI, Paris: ICC Publications, v. 18, n. 1, p. 65, 2007.

KURATOWSKI, Roman. K. Limitation of actions founded on contract and prescription of contractual obligations in Private International Law. Estratto Dagli Atti del Terzo Congresso di Diritto Comparato. Roma: Edizione Dell'Istituto Italiano di Sudi Legislativi, 1955. v. 3, p. 447.

LAGARDE, Paul. Recherches sur l'ordre public en droit international privé. Paris: LGDJ, 1959. v. 15.

LAUZERAL, Philippe; BOULFROY, Marion. Qui peut engager une procédure d'arbitrage?. Recueil Dalloz Sirey, Paris: Dalloz, n. 16, p. 1100-1101, 2008.

LEBEDEV, Sergei. How long does a foreign award saty enforceable?. The Art of Arbitration. Essays on International Arbitration. Liber Amicorum Pieter Sanders. The Netherlands: Kluwer law and Taxation Publishers, 1982. p. 213.

LEE, João Bosco. A especificidade da arbitragem comercial internacional. In: CASELLA Paulo Borba (Coord.). Arbitragem: lei brasileira e praxe internacional. 2. ed. rev. e ampl. São Paulo: LTr, 1999. p. 186. 
—. A internacionalidade da arbitragem - A lei aplicável à prescrição - A interrupção do prazo prescricional em procedimento arbitral (parecer). Estudos de arbitragem. Curitiba: Juruá, 2008. p. 357-375.

—. A Lei 9.307/96 e o direito aplicável ao mérito do litígio na arbitragem comercial internacional. Revista de Direito Bancário, do Mercado de Capitais e da Arbitragem, São Paulo: RT, v. 11, p. 355, 2001.

Arbitragem comercial internacional nos Países do Mercosul. Curitiba: Juruá, 2002.

- Renault vs. CAOA. Revista Brasileira de Arbitragem, São Paulo: ThomsonIOB, n. 3, p. 134, jul.-set. 2004.

LEMES, Selma Ferreira. A arbitragem e a decisão por equidade no direito brasileiro e comparado. Arbitragem: estudos em homenagem ao Prof. Guido Fernando da Silva Soares (in memoriam). São Paulo: Atlas, 2007. p. 197.

A inteligência do art. 19 da Lei de Arbitragem (instituição da arbitragem) e as medidas cautelares preparatórias. Revista de Direito Bancário, do Mercado de Capitais e da Arbitragem, São Paulo: RT, v. 20, p. 411, abr.-jun. 2003.

LEW, Julian D. M.; MISTELIS, Loukas A.; KROLL, Stefan M. Comparative International Commercial Arbitration. The Hague: Kluwer Law International, 2003.

LIMA, Cláudio Vianna de. A arbitragem no tempo - o tempo na arbitragem. In: GARCEZ, José Maria Rossani (Coord.). A arbitragem na era da globalização. 2. ed. Rio de Janeiro: Forense, 1999. p. 5.

LIMA, Leandro Rigueira Rennó. Arbitragem: uma análise da fase pré-arbitral. Belo Horizonte: Mandamentos, 2003.

LOQUIN, Eric. À la recherche de la jurisprudence arbitrale. Revista de Arbitragem e Mediação, São Paulo: RT, n. 20, p. 149, jan.-mar. 2009.

—. À propos de l'ouvrage d'Emmanuel Gaillard: Aspects philosophiques du droit de l'arbitrage international. Revue de l'Arbitrage, Paris: Comité Français de l'Arbitrage, n. 2, p. 317, 2004.

—. L'amiable composition en droit comparé et international. Paris: Libraries Techniques, 1980. 
—. Nota sobre a decisão proferida pela Corte de Cassação Francesa (Cass. Civ. 2. $\left.{ }^{a}\right)$, j. 15.02.2001. Revue de l'arbitrage, Paris: Comité français de l'arbitrage, n. 1, p. $141,2001$.

MAGALHÃES, José Carlos. A arbitragem e o processo judicial. Revista do Advogado, São Paulo: AASP, ano XXVI, n. 87, p. 61, 2006.

—. Arbitragem internacional privada. In: —— BAPTISTA, Luiz Olavo. Arbitragem comercial. Rio de Janeiro: Freitas Bastos, 1986. p. 17.

—. A tardia ratificação da Convenção de Nova Iorque sobre arbitragem: um retrocesso desnecessário e inconveniente. Revista de Arbitragem e Mediação, São Paulo: RT, ano 5, n. 18, p. 24, 2008.

—. Sentença arbitral estrangeira. Incompetência da justiça brasileira para anulação. Competência exclusiva do STJ para apreciação da validade em homologação. Revista de Arbitragem e Mediação, São Paulo: RT, v. 1, n. 1, p. 135, jan.-abr. 2004.

MAGALHÃES, Rodrigo de Almeida. Arbitragem e convenção arbitral. Belo Horizonte: Mandamentos, 2006.

MALAURIE, Philippe. Exposé des Motifs. Avant-projet de réforme du droit des obligations et de la prescription. Paris: La documentation française, 2008. p. 196.

MALINVAUD, Philippe. Droit des obligations. 7. ed. Paris: Litec, 2001.

MANTILLA-SERRANO, Fernando. A nova Lei de Arbitragem na Espanha. Revista Brasileira de Arbitragem, São Paulo: Thomson-IOB, n. 2, p. 109, abr.-jun. 2004.

MARCATO, Antonio Carlos. Interrupção da prescrição: o inciso I do artigo 202 do Código Civil. In: CIANCI, Mirna (Coord.). Prescrição no Código Civil: uma análise interdisciplinar. 2. ed. São Paulo: Saraiva, 2006. p. 14.

MARTINS, Pedro A. Batista. Apontamentos sobre a Lei de Arbitragem. Rio de Janeiro: Forense, 2008.

—. Aspectos jurídicos do compromisso. In: —— LEMES, Selma Ferreira; CARMONA, Carlos Alberto. Aspectos fundamentais da Lei de Arbitragem. Rio de Janeiro: Forense, 1999. p. 232.

—. As três fases da arbitragem. Revista do Advogado, São Paulo: AASP, ano XXVI, n. 87, p. 87, 2006.

MAYER, Pierre; HEUZÉ, Vincent. Droit international privé. 9. ed. Paris: Montchrestien, 2007. 
MENDES, Rodrigo Octávio Broglia. Regras imperativas e arbitragem internacional: por um direito transnacional privado? Revista de Arbitragem e Mediação, São Paulo: RT, v. 19, p. 31, 2008.

NAÓN, Horacio Grigera. Les Principes d'Unidroit relatifs aux contrats du commerce international. Bulletin de la cour internationale de da CCI, Paris: ICC Publications, Supplément spécial, p. 161, 2002.

NASCIMENTO E SILVA, G.E.; ACCIOLY, Hildebrando. Manual de direito internacional público. São Paulo: Saraiva, 1998.

NEVES, Gustavo Kloh Muller. Prescrição e decadência no direito civil. Rio de Janeiro: Lumen Juris, 2006.

NHERING, Carlos. Sentenças parciais. Revista Brasileira de Arbitragem, Porto Alegre: Thomson-IOB, ano IV, n. 14, p. 23, 2007.

NICOLAU JR., Mauro; ALMEIDA, Ricardo Marques de. Prescrição, cláusulas gerais e segurança jurídica. Perspectivas hermenêuticas dos direitos fundamentais no Código Civil. In: CIANCI, Mirna (Coord.). Prescrição no Código Civil: uma análise interdisciplinar. 2. ed. São Paulo: Saraiva, 2006. p. 201.

NIDDAM, Laurent. L'exécution des sentences arbitrales internationales aux États-Unis. Revue de l'arbitrage Paris: Comité français de l'arbitrage, n. 1, p. 27, 1993.

NORTH, P.M.; FAWCET, J.J. Cheshire and North's Private International Law. Londres: Butterworths, 1992.

ODA, Hiroshi. La reforme de l'arbitrage au Japon. Bulletin de la Cour international d'arbitrage de la CCI, Paris: ICC Publications, v. 15, n. 1, p. 32, 2004.

OLIVEIRA, Antonio de Almeida. A prescrição em direito commercial e civil. Lisboa: Livraria Clássica Editora, 1914.

OPPETIT, Bruno. Justice étatique et justice arbitrale. Études offertes à Pierre Bellet. Paris: Litec, 1991. p. 415.

—. Nota sobre a decisão proferida pela Corte de Apelação de Paris, 30/11/1972. Journal du Droit International, p. 394, 1973.

—. Philosophie de l'arbitrage commercial international. Journal du Droit International, n. 4, p. 811, 1993.

—. Théorie de l'arbitrage. Paris: PUF, 1998.

PANZA, Giuseppe. Contributo allo studio della prescrizione. Jovene: Facoltà giuridica dell'Università di Bari, 1984. v. 76. 
PARENTE, Eduardo de Albuquerque. Processo arbitral e sistema. 2010. Tese (Doutoramento) - Faculdade de Direito da Universidade de São Paulo, São Paulo. No prelo.

PELLERIN, Jacques. Nota sobre a decisão da proferida pela Corte de Cassação Francesa (2. ${ }^{a}$ Ch. Civ.) em 11 dez. 1985, Guilbert c/Société de Développement de transport artisanal par eaux (S.D.T.A.E). Revue de l'arbitrage Paris: Comité français de l'arbitrage, p. 387, 1987.

PEREIRA, Caio Mário da Silva. Instituições de direito civil. 18. ed. Rio de Janeiro: Forense, 1997. v. 1.

PEREIRA, Izabel de Albuquerque. A ordem pública nas arbitragens comerciais internacionais. $O$ direito internacional contemporâneo: estudos em homenagem ao Professor Jacob Dolinger. Rio de Janeiro: Renovar, 2006. p. 524.

PHILONENKO, Maximilien. De la prescription extinctive en droit international privé. Mélanges 1872/1937, Extrait du Journal du droit international. Paris, 1936, p. 274.

PINTO, Roger. La prescription en droit international. Recueil des cours de l'académie de droit international de La Haye, t. 1 p. 387-455, 1955.

POMMIER, Jean-Cristophe. Principe d'autonomie et loi du contrat en droit international privé. Paris: Economica, 1992.

PONTES DE MIRANDA. Tratado de direito privado: parte geral. Rio de Janeiro: Borsoi, 1955. t. VI.

POUDRET, Jean-François; BESSON, Sébastien. Comparative Law of International Arbitration. 2. ed. Londres: Sweet \& Maxwell, 2007.

PUCCI, Adriana Noemi. Homologação de sentenças arbitrais estrangeiras. Arbitragem: estudos em homenagem ao Prof. Guido Fernando da Silva Soares (in memoriam). São Paulo: Atlas, 2007. p. 347-350.

RACINE, Jean-Baptiste. Réflexions sur l'autonomie de l'arbitrage commercial international. Revue de l'Arbitrage, Paris: Comité Français de l'Arbitrage, n. 2, p. 305, 2005 .

RECHSTEINER, Beat Walter. Direito internacional privado. Teoria e prática. 11. ed. rev. e atual. São Paulo: Saraiva, 2008.

REDFERN, Alan; HUNTER, Martin. Law and Practice of International Commercial Arbitration. London: Sweet \& Maxwell, 1991. 
REDMOND-COOPER, Ruth. Limitation of Actions. London: Sweet \& Maxwell, 1992.

REIMANN, Mathias. Comparative Law and Private International Law. The Oxford Handbook of Comparative Law. Edited by Mathias Reinmann and Reinhard Zimmermann. Oxford: University Press, 2008. p. 1384.

REYMOND, Claude. L'arbitration act, 1996. Convergence et originalité. Revue de l'arbitrage, Paris: Comité français de l'arbitrage, n. 1, p. 61, 1997.

ROBERT, Jean. De la règle de conflit à la règle matérielle d'arbitrage international (spécialement en droit international privé français). The Art of Arbitration. Essays on International Arbitration. Liber Amicorum Pieter Sanders. The Netherlands: Kluwer law and Taxation Publishers, 1982. p. 273.

; MOREAU, Bertrand. L'arbitrage: Droit interne et droit international privé. 5. ed. Paris: Dalloz, 1983.

RODRIGUES, Silvio. Direito civil: parte geral. 26. ed. São Paulo: Saraiva, 1996.

ROOS, Cristian Conejero; GRION, Renato Stephan. L'arbitrage au Brésil: droit et pratique dans une optique CCI. Bulletin de la Cour international d'arbitrage de la CCI, Paris: ICC Publications, v. 17, n. 2, p. 31, 2006.

RUBINO-SAMMARTANO. International Arbitration. Law and Practice. 2. ed. The Hague: Kluwer Law International, 2001.

SACCO, Rodolfo. Introdução ao direito comparado. Tradução de Véra Jacob de Fradera. São Paulo: RT, 2001.

SAMUEL, Adam. Jurisdictional Problems in International Commercial Arbitration: A Study of Belgian, Dutch, English, French, Swedish, Swiss, U.S. and West German Law. Zurique: Schulthess Polygraghischer, 1989.

SANDERS, Pieter. Trends in International Commercial Arbitration. Recueil des cours de l'académie de droit international de La Haye, v. 145, p. 245, 1975.

SANTOS, Francisco Cláudio de Almeida. Os princípios fundamentais da arbitragem. In: CASELLA Paulo Borba (Coord.). Arbitragem: lei brasileira e praxe internacional. 2. ed. rev. e ampl. São Paulo: LTr, 1999. p. 119-120.

SCHILLER, Johathan D. Applying the Law Governing the Arbitration Procedure: Sensibility and Without Excessive Formality. International Council for Commercial Arbitration (ICCA) Congress Series nr. 9: Improving the Efficiency of Arbitration Agreements and Awards: 40 years of Application of the New York Convention. The Hague: Kluwer Law International, 1999. p. 391. 
SCHLESINGER, Rudolf B.; BAADE, Hans W.; HERZOG, Peter E.; WISE, Edward M. Comparative Law: Cases - Text - Materials. New York: Foundation Press, 1998.

SCHWENZER, Ingeborg; MANNER, Simon. The Claim is Time-Barred: The Proper Limitation Regime for International Sales Contracts in International Commercial Arbitration. Arbitration International, London: Kluwer Law, v. 23, n. 2, p. 293, 2007.

SILVA, Agustinho Fernandes Dias da. Introdução ao direito internacional privado parte especial: os conflitos de leis no espaço (principalmente em face do direito brasileiro). Rio de Janeiro: Freitas Bastos, 1978. v. 2.

SIQUEIROS, José Luis. Los nuevos principios de Unidroit (2004) sobre contratos comerciales internacionales. $O$ direito internacional contemporâneo: estudos em homenagem ao Professor Jacob Dolinger. Rio de Janeiro: Renovar, 2006. p. 572.

SMITS, Jan M. Comparative Law and its Influence on National Legal Systems. In: REINMANN, Mathias; ZIMMERMANN, Reinhard (Ed.). The Oxford Handbook of Comparative Law. Oxford: University Press, 2008. p. 519.

STETNER, Renato Pereira; PITOMBO, Eleonora Coelho. A Convenção de Nova York: ratificação pelo Brasil. In: VERÇOSA, Haroldo Malheiros Duclerc (Org.). Aspectos da arbitragem institucional: 12 anos da Lei 9.307/96. São Paulo: Malheiros, 2008. p. 54.

STRENGER, Irineu. Arbitragem comercial internacional. São Paulo: LTr, 1996.

—. Comentários à Lei Brasileira de Arbitragem. São Paulo: LTr, 1998.

—. Contratos internacionais do comércio. 4. ed. São Paulo: LTr, 2003.

- Direito internacional privado. 6. ed. São Paulo: LTr, 2005.

TACKABERRY, John; MARRIOTT, Arthur. Bernstein's Handbook of Arbitration and Dispute Resolution Practice. 4. ed. London: Sweet \& Maxwell, 2003. v. 1.

TAISNE, Jean-Jacques. Nota sobre Cass, civ., 2. a 11 dez. 1985, JCP, II, Jurisprudence. Paris, seção 20676/20677, 1986.

TELES, Miguel Galvão. Arbitragem comercial internacional ex aequo et bono e determinação de lei de mérito. Revista de Arbitragem e Mediação, São Paulo: RT, n. 19, p. 81, 2008.

TENÓRIO, Oscar. Direito internacional privado. 11. ed. rev. e atual. por Jacob Dolinger. Rio de Janeiro: Freitas Bastos, 1976.

TERCIER, Pierre. Rôles et Défis de l'Arbitrage Institutionnel. Revista de Arbitragem e Mediação, São Paulo, v. 3, n. 9, p. 22, abr.-jun. 2006.

TERRÉ, François; SIMLER, Philippe; LEQUETTE, Yves. Droit civil: Les obligations. 8. ed. Paris: Dalloz, 2002. 
THEODORO JÚNIOR, Humberto. A exceção de prescrição no processo civil. Impugnação do devedor e decretação de ofício pelo juiz. In: FABRÍCIO, Adroaldo Furtado; CARNEIRO, Paulo Cezar Pinheiro (Coord.). Meios de impugnação ao julgado civil. Estudos em homenagem a José Carlos Barbosa Moreira. Rio de Janeiro: Forense, 2007. p. 303.

- Curso de direito processual civil: processo de execução e processo cautelar. 45. ed. Rio de Janeiro: Forense, 2010. v. 2.

—. Direito estrangeiro: prescrição cambiária. Parecer (Material não publicado, cedido com autorização do autor.)

—. Distinção científica entre prescrição e decadência. Um tributo à obra de Agnelo Amorim Filho. Revista dos Tribunais, São Paulo: RT, ano 94, v. 836, p. 49, 2005.

—. Prescrição e decadência no novo Código Civil: alguns aspectos relevantes. Disponível em: <http://www.iobonlinejuridico.com.br>. Acesso em: 5 dez. 2010.

—. Prescrição - Liberdade e dignidade da pessoa humana. Revista Dialética de Direito Processual, São Paulo: Dialética, n. 40, p. 64, jul. 2006.

—. Processo de execução e cumprimento de sentença. São Paulo: Leud, 2009.

TIBÚRCIO, Carmen. A lei aplicável às arbitragens internacionais. In: MARTINS, Pedro A. Batista; GARCEZ, José Maria Rossani (Coord.). Reflexões sobre arbitragem. São Paulo: LTr, 2002. p. 100.

VALENÇA FILHO, Clávio de Melo. Aspectos de direito internacional privado na arbitragem. Estudos de arbitragem. Curitiba: Juruá, 2008. p. 269-283.

—. Poder Judiciário e sentença arbitral. Curitiba: Juruá, 2003.

—. Tutela judicial de urgência e a lide objeto de convenção de arbitragem. Revista Brasileira de Arbitragem, Porto Alegre: Thomson-IOB, ano II, n. 7, p. 7 e ss., jul.-set. 2005.

VALLADÃO, Haroldo. Direito internacional privado. Rio de Janeiro: Faculdade de Direito da UFRJ, 1966.

—. 5. ed. Rio de Janeiro: Freitas Bastos, 1980.

VAN DEN BERG, Albert Jan. The New York Arbitration Convention of 1958: Towards a Uniform Judicial Interpretation. The Netherlands: Kluwer Law, 1981.

VAZ SERRA, Adriano Paes da Silva. Prescrição extintiva e caducidade: estudo de direito civil português, de direito comparado e de política legislativa. Lisboa: BMJ, 1961. n. 106. 
VERÇOSA, Fabiane. Arbitragem interna v. Arbitragem internacional: Breves contornos da distinção e sua repercussão no ordenamento jurídico brasileiro face ao princípio da autonomia da vontade. $O$ direito internacional contemporâneo: estudos em homenagem ao professor Jacob Dolinger. Rio de Janeiro: Renovar, 2006. p. 440-441.

VERYKIOS, P.A. La prescription en droit international public. Paris: Pedone, 1934.

VIANA, Aldir Dias. Da prescrição no direito civil brasileiro. Rio de Janeiro: Forense, 1983.

VON MEHREN, Arthur Taylor. Limitations on Party Choice of Governing Law: do they exist for International Commercial Arbitration?. The Mortimer and Raymond Sackler Institute of Advanced Studies. Tel Aviv University, 1986.

VON TUHR, Andreas. Derecho civil. Buenos Aires: Depalma, 1948. v. 3.

WALTON, Anthony. Russel on the Law of Arbitration. London: Stevens \& Sons Limited, 1970.

WAMBIER, Teresa Arruda Alvim. Nulidades do processo e da sentença. 6. ed. São Paulo: RT, 2007.

WEINTRAUB, David A. When do Statutes of Limitation Apply in Arbitration?. The Nebraska Lawyer, p. 24, nov.-dec 2007.

WISE, Edward M. The Transplant of Legal Patterns. The American Journal of Comparative Law, v. 38, p. 5, 1990.

YAMAMOTO, Kazuhifo. La nouvelle loi japonaise sur l'arbitrage. Revue de l'arbitrage, Paris: Comité français de l'arbitrage, n. 4, p. 837-838, 2004.

ZIMMERMANN, Reinhard. Comparative Foundations of a European Law of Set-Off and Prescription. Cambridge: Cambridge University Press, 2002.

ZWEIGERT, Konrad; KÖTZ, Hein. Introduction to Comparative Law: The Framework. $2^{\text {nd }}$ ed. rev. Translated from the German by Tony Weir. Oxford: Clarendon Press, 1987. v. 1 .

\section{II - DECISÕES NACIONAIS E ESTRANGEIRAS}

\section{Decisões nacionais}

STF, Tribunal Pleno, CR 5885 AgR/DF, Ag.reg. na Carta Rogatória, rel. Min. Sydney Sanches, j. 04.11.1992, DJ 11.12.1992, p. 23662. 
STJ, 1. ${ }^{a}$ Turma, REsp 588.202/PR, rel. Min. Teori Albino Zavascki, j. 10.02.2004, DJ 25.02.2004.

STJ, 2. ${ }^{a}$ Turma, REsp 608.478/PE, rel. Min. Francisco Peçanha Martins, j. 11.10.2005, DJ 14.11.2005.

STJ, 3. a Turma, REsp 616/RJ, rel. Min. Cláudio Santos, j. 24.04.1990, RSTJ 37/263.

STJ, 3. ${ }^{\text {a }}$ Turma, REsp 712566/RJ, rel. Min. Nancy Andrighi, j. 18.08.2005, DJ 05.09.2005, p. 407.

STJ, 3. ${ }^{\text {a }}$ Turma, REsp 598.798/RS, rel. Min. Carlos Alberto Menezes Direito, j. 06.09.2005, DJ 21.11.2005.

STJ, 3. ${ }^{\text {a }}$ Turma, REsp 15.261-0/SP, rel. Min. Eduardo Ribeiro, j. 10.08.1992, DJ 21.09.1992.

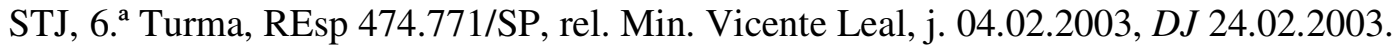

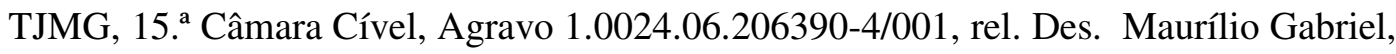
j. 1. ${ }^{\circ}$ 12.2006, DJ 23.01.2007, Revista Brasileira de Arbitragem, Porto Alegre: IOB, n. 16, p. 127-140, out.-nov.-dez. 2007.

TJMG, 14. ${ }^{a}$ Câmara Cível do TJMG, Agravo 1.0024.07.600275-7/002, rel. Des. Elias Camilo, j. 17.01.2008, DJ 11.02.2008.

TRF 2.. Região, 6. ${ }^{\mathrm{a}}$ Turma Especializada, rel. Des. Guilherme Couto, Agravo de Instrumento: AG 170344/RJ, 2008.02.01.016468-1, j. 23.03.2009, DJU 02.04.2009, p. 113.

Tribunal de Alçada do Estado e Minas Gerais, 5. ${ }^{a}$ Câmara Civil, Ap. Civ. 393.297-8, rel. Juiz Mariné da Cunha, j. 15.05.2003, Revista Brasileira de Arbitragem, Porto Alegre: Thomson-IOB, ano II, n. 7, p. 134-142.

\section{Decisões estrangeiras}

Caso "Patiño", Corte de Cassação francesa (Ch. Civ. 1 sec), 15.06.1963, Les grands arrêts de la jurisprudence française de droit international privé. 5. ed. Paris: Dalloz, p. 330.

Corte de Apelações de Lyon (1. ${ }^{a}$ Ch.), j. 1. ${ }^{\circ} .07 .1993$ (caso "Finapar"), com nota de Philippe Fouchard, Revue de l'arbitrage, Paris: Comité français de l'arbitrage, n. 1, p. 102-106, 1995. 
Corte de Apelações de Nova York, decisão 24.03.2005, Diamond Waterproofing Systems, Inc. v. 55 Liberty Owners Corp. in Westlaw 4 N.Y.3d 247, 826 N.E.2d 802, 793 N.Y.S2d 831.

Corte de Apelações de Paris, decisão 26.03.1991, Dalico, Revue de l'Arbitrage, p. 456, 1991.

Corte de Apelações de Paris, 1. ${ }^{a}$ Câmara Civil, Ministère tunisien de l'Equipement c/société Bec Frères, j. 24.02.1994, Revue de l'arbitrage, n. 2, 1995, nota de Yves Gaudemet.

Corte de Apelações de Paris (1. ${ }^{a}$ Ch., sect. C), 03.03.1994. Revue critique de droit international privé, Paris, n. 83, (3), p. 532-545, jul.-set. 1994, nota de Bertrand Ancel.

Corte de Cassação francesa (Cass. Civ. 2.a), j. 15.02.2001. Revue de l'arbitrage, Paris: Comité français de l'arbitrage, n. 1, p. 135-156, 2001, nota de Eric Loquin.

Corte de Cassação francesa (1. ${ }^{\mathrm{a}}$ Ch. Civ.), j. 21.04.1971. Revue critique de droit international prive, p. 74, 1972, nota de Paul Lagarde; e Corte de Cassação francesa (1. ${ }^{\text {a }}$ Ch. Civ), 07.06.1977, Revue critique de droit international privé, p. 119, 1978, nota de Henri Batiffol.

Corte de Cassação francesa (2. ${ }^{a}$ Ch. Civ.), j. 11.12.1985, Guilbert c/Société de Développement de transport artisanal par eaux (S.D.T.A.E), com nota de Jacques Pellerin, Revue de l'arbitrage, Paris: Comité français de l'arbitrage, p. 387-390, 1987.

Corte de Cassação francesa, 1. ${ }^{a}$ Câmara Civil, j. 20.12.1993. Dalico, Journal du droit international, n. 2, p. 432, 1994, nota de Emmanuel Gaillard.

Corte de Cassação francesa (1. ${ }^{a}$ Ch. Civ.), decisão de 30.06.1998. Mediterranean shipping Co c/ URCOOPA, com nota de Marie-Laure Niboyet, Revue de l'arbitrage, Paris: Comité français de l'arbitrage, n. 1, p. 80-85, 1999.

Corte de Cassação francesa, decisão 05.03.1957, RTD Civ. 1957/720, com comentários de P. Hébraud.

Corte de Cassação francesa (1. ${ }^{\text {a }}$ Ch. Civ), j. 15.06.1994 (caso "Sonidep"), com nota de Emmanuel Gaillard, Revue de l'arbitrage, n. 1, Paris: Comité français de l'arbitrage, p. 88-101, 1995.

Corte Suprema da Califórnia, decisão 21.05.2007, Wagner Construction Company v. Pacific Mechanical Corporation in 2007 Westlaw 41 Cal. 4th 19, 157 P.3d 1029, 58 Cal. Rptr. 3d 434.

1. a Câmara Cível da Corte de Cassação Francesa, decisão 07.05.1963, Gosset, JCP, 1963.II.13405. Paris: Lexisnexis Jurisclasseur, nota de B. Goldman, Journal du Droit 
International, 1964, p. 82, 1. ${ }^{\text {a }}$ esp., nota de J.D. Bredin; Recueil Dalloz 1963. Paris: Éditions Dalloz, p. 545, nota de Jean Robert.

Sentença proferida no caso CCI n. 2.074 de 1973 In: JARVIN, Sigvard; DERAINS, Yves. Collection of ICC Arbitral Awards (1974-1985). The Netherlands: Kluwer Law, p. 232.

Sentença proferida no caso CCI n. ${ }^{\circ} 2.462$ de 1974 Sentença proferida no caso CCI n. ${ }^{\circ}$ 2.074 de 1973 In: JARVIN, Sigvard; DERAINS, Yves. Collection of ICC Arbitral Awards (1974-1985). The Netherlands: Kluwer Law, p. 232.

Sentença proferida no caso CCI n. 4.131 de 1982. In: JARVIN, Sigvard; DERAINS, Yves. Collection of ICC Arbitral Awards (1974-1985). The Netherlands: Kluwer Law, 1994. p. 470.

Sentença proferida no caso CCI n. ${ }^{\circ} 4.265$ de 1984 In: JARVIN, Sigvard; DERAINS, Yves. Collection of ICC Arbitral Awards (1974-1985). The Netherlands: Kluwer Law, 1994, p. 499-501, nota de Yves Derains.

Sentença proferida no caso CCI n. 4.491 de 1985. In: JARVIN, Sigvard; DERAINS, Yves. Collection of ICC Arbitral Awards (1974-1985). The Netherlands: Kluwer Law, 1994. p. 539, nota de Sigvard Jarvin.

Sentença proferida no Caso CCI n. ${ }^{\circ} 4.862$ de 1986. In: JARVIN, Sigvard; DERAINS, Yves; ARNALDEZ, J.J. Collection of ICC Arbitral Awards (1986-1990). The Netherlands: Kluwer Law, 1994. p. 308.

Sentença proferida no caso CCI n. 5.460 de 1987. In: JARVIN, Sigvard; DERAINS, Yves; ARNALDEZ, J.J. Collection of ICC Arbitral Awards (1986-1990). The Netherlands: Kluwer Law, 1994. p. 138.

Sentença proferida no Caso CCI n. 6.230 de 1990. JARVIN, Sigvard; DERAINS, Yves; HASCHER, Dominique. Collection of ICC Arbitral Awards (1991-1995). The Netherlands: Kluwer Law, 1997. p. 86.

Sentença preliminar proferida no caso CCI n. 6.371 de 1989. Bulletin de la cour intrnationale d'arbitrage de la CCI, Paris: ICC Publication, v. 13, n. 2, p. 64-67, 2002.

Sentença proferida no Caso CCI n. ${ }^{\circ} 6.573$ de 1991. In: JARVIN, Sigvard; DERAINS, Yves; HASCHER, Dominique. Collection of ICC Arbitral Awards (1991-1995). The Netherlands: Kluwer Law, 1997. p. 382.

Sentença final proferida no caso CCI n. ${ }^{\circ} 7.144$ de 1992. Bulletin de la cour international d'arbitrage de la CCI, Paris: ICC Publication, v. 13, n. 2, p. 72-73, 2002. 
Sentença parcial proferida no caso CCI n. ${ }^{\circ} 7.263$ de 1994. In: ARNALDEZ, J.J.; DERAINS, Yves; HASCHER, Dominique. Collection of ICC Arbitral Awards (19962000). The Netherlands: Kluwer Law, 2003. p. 89-90.

Sentença final proferida no caso CCI n. ${ }^{\circ} 7.263$ de 1996. ICC International Court of Arbitration Bulletin, Paris: ICC Publication, v. 15, n. 1, p. 72, 2004.

Sentença final proferida no caso CCI n. ${ }^{\circ} 7.301$ de 1993. In: ARNALDEZ, J.J.; DERAINS, Yves; HASCHER, Dominique. Collection of ICC Arbitral Awards (19962000). The Netherlands: Kluwer Law, 2003. p. 192.

Sentença Parcial proferida no caso CCI n. 7.375 de 1996. ICC International Court of Arbitration Bulletin, Paris: ICC Publications, v. 11, p. 37, 2001.

Sentença Parcial proferida no caso CCI n. 7.375 de 1996 (Ministry of Defense and Support for Armed Forces of the Islamic Republic of Iran v. Westinghouse Electric Corp.) de 1996. Mealey's International Arbitration Report, v. 11, dez. 1996.

Sentença parcial proferida no caso CCI n. 7.710 de 1995. In: ARNALDEZ, JeanJacques; JARVIN, Sigvard; DERAINS, Yves; JOLIVET, Emmanuel. Chronique de sentences arbitrales de la Cour d'arbitrage de la Chambre de commerce internationale. Journal du Droit International, n. 4, p. 1147-1164, 2001.

Sentença proferida no caso CCI n. 9.102 de 1998. ICC International Court of Arbitration Bulletin, Paris: ICC Publication, v. 16, n. 1, p. 98, 2005.

Sentença proferida no Caso CCI n. 9.103 de 2000, com nota de JOLIVET, Emmanuel. Chronique de jurisprudence arbitrale de la Chambre de commerce internationale (CCI). Les cahiers de l'arbitrage. Paris: Pedone, 2009. p. 42.

Sentença final CCI proferida no caso n. $^{\circ} 9.154$ de 1998. Bulletin de la cour intrnationale d'arbitrage de la CCI, Paris: ICC Publication, v. 11, n. 1, p. 100-105, 2000 .

Sentença proferida no caso CCI n. 10.452 de 2001. ICC International Court of Arbitration Bulletin, Paris: ICC Publication, v. 16, n. 1, p. 107, 2005.

Sentença proferida no caso CCI n. 10.728 de 2001. ICC International Court of Arbitration Bulletin, Paris: ICC Publications, v. 18, n. 1, p. 98, 2007.

Sentença final proferida no caso CCI n. 10.900 de 2001. Cahiers de l'arbitrage, v. 4, Paris: Pedone, p. 369-371, 2008, nota de Emmanuel Jolivet.

Sentença proferida no Caso CCI n. ${ }^{\circ} 11.039$ de 2002. ICC International Court of Arbitration Bulletin, Paris: ICC Publication, v. 19, n. 2, p. 95, 2008. 
Sentença final proferida no caso CCI n. ${ }^{\circ} 11.277$ de 2003. In: ARNALDEZ, J.J.; HASCHER, Dominique; DERAINS, Yves. Collection of ICC Arbitral Awards (20012007). The Netherlands: Kluwer Law International, p. 739, nota de Sigvard Jarvin.

Sentença proferida no caso CCI n. 11.409 de 2002. ICC International Court of Arbitration Bulletin, Paris: ICC Publications, v. 18, n. 1, p. 100-104, 2007.

United States District Court for the Northern District of Texas, Dallas Division, Civil Action n. 3:03-CV-0406-G, 23.10.2003, Gulf Petro Trading Company Inc. v. Nigerian National Petroleum Corporation, Asa Bulletin The Netherlands: Kluwer Law, v. 22, n. 1, p. 153-168, 2004.

\section{III - WEBSITES CONSULTADOS}

<http://www.uncitral.org/pdf/english/yearbooks/yb-1979-e/vol10-p145-173-e.pdf>. Acesso em: 22 out. 2010.

<http://www.uncitral.org/pdf/english/texts/arbitration/ml-arb/07-86998_Ebook.pdf>. Acesso em: 22 out. 2010.

<http://civil.udg.es/normacivil/estatal/contract/Larbr-03.htm>. Acesso em: 23 out. 2010. $<$ http://www.ccbc.org.br/arbitragem.asp?subcategoria=regulamento português $>$. Acesso em: 31 out. 2010.

<http://www.camaradearbitragemsp.org.br/>. Acesso em: 31 out. 2010.

<http://www.arbitac.com.br/pt/regulamento_arb.php\#5>. Acesso em: 31 out. 2010. $<$ http://www.iccwbo.org>. Acesso em: 31 out. 2010.

$<$ http://www.lcia.org/LCIA_folder/documents/LCIAEnglisharbitrationrules.pdf > . Acesso em: 2 nov. 2010.

$<\mathrm{http}$ //www.uncitral.org/pdf/english/texts/arbitration/arb-rules/arb-rules.pdf $>$. Acesso em: 2 nov. 2010.

<http://www.uncitral.org/uncitral/fr/uncitral_texts/sale_goods/1974Convention_status.h tml>. Acesso em: 12 nov. 2010. 
<http://supreme.justia.com/us/337/163/case.html>. Acesso em: 12 nov. 2010.

<http://www.idi-iil.org/idiF/resolutionsF/1925_haye_01_fr.pdf>. Acesso em: 18 nov. 2010 .

<http://www.idi-iil.org/idiF/resolutionsF/1924_vien_02_fr.pdf>. Acesso em: 19 nov. 2010.

$<$ http://www.uncitral.org/uncitral/fr/uncitral_texts/sale_goods/1974Convention_status.h tml>. Acesso em: 22 nov. 2010.

<http://www.uncitral.org/pdf/english/yearbooks/yb-1979-e/vol10-p145-173-e.pdf>.

Acesso em: 24 nov. 2010.

<http://www.unidroit.org/english/principles/contracts/main.htm>. Acesso em: 23 nov. 2010.

$<\mathrm{http} / / /$ www.unidroit.org/english/principles/civilprocedure/main.htm>. Acesso em: 23 nov. 2010.

<http://www.uncitral.org/pdf/english/yearbooks/yb-1979-e/vol10-p145-173-e.pdf>.

Acesso em: 25 nov. 2010.

$<$ http://www.uncitral.org/uncitral/en/uncitral_texts/sale_goods/1974Convention_status.

html>. Acesso em: 25 nov. 2010.

http://www.kantei.go.jp/foreign/policy/sihou/arbitrationlaw.pdf>. Acesso em: 29 nov. 2010

<http://www.cbar.org.br/leis_internacionais/lei_italia.html>. Acesso em: 29 nov. 2010.

$<$ http://www.cbar.org.br/leis_internacionais/lei_alemanha.html>. Acesso em: 2 dez. 2010.

<http://www.uncitral.org/pdf/english/yearbooks/yb-1979-e/vol10-p145-173-e.pdf>, p. 161. Acesso em: 2 dez. 2010.

$<$ http://www.unidroit.org/english/principles/contracts/main.htm>. Acesso em: 3 dez. 2010.

<http://cisgw3.law.pace.edu/cases/947565i1.html>. Acesso em: 3 dez. 2010.

<http://cisgw3.law.pace.edu/cases/947660i1.html>. Acesso em: 3 dez. 2010.

$<$ http://www.uncitral.org/pdf/english/texts/arbitration/ml-arb/07-86998_Ebook.pdf>.

Acesso em: 3 dez. 2010.

$<$ http://www.uncitral.org/pdf/english/texts/arbitration/arb-rules/arb-rules.pdf>. Acesso em: 3 dez. 2010.

<http://www.search.e-laws.gov.on.ca/en/search/>. Acesso em 5 dez. 2010. 
$<$ http://www.unidroit.org/english/principles/civilprocedure/main.htm>. Acesso em 6 dez. 2010.

<http://www.uncitral.org/pdf/english/yearbooks/yb-1979-e/vol10-p145-173-e.pdf>, p. 161. Acesso em: 9 dez. 2010 